\title{
HACIA UN INJUSTO PENAL DE LA CRIMINALIDAD ORGANIZADA. UNA PROPUESTA A MODO DE LEGE FERENDA*
}

\section{Raúl CarneVali RodrígueZ**}

RESUMEN: El crimen organizado se ha constituido como una de las manifestaciones criminales de los nuevos tiempos, marcado por el fenómeno de la globalización. Así se puede apreciar a través de los diversos instrumentos internacionales que se han aprobado en los últimos años. Si bien los delitos asociativos se encuentran consagrados en los Códigos punitivos desde el siglo XIX, la criminalidad organizada conformaría una modalidad específica de asociación ilícita que se expresaría por su mayor peligrosidad. De allí pues, la necesidad de elaborar una propuesta normativa que recoja el especial desvalor de esta clase de comportamientos. En este contexto, el trabajo se dirige a examinar dos materias en particular. La primera apunta a precisar el objeto de protección de los delitos asociativos y los criterios de imputación. El segundo tema es la elaboración de normas penales referidas a la criminalidad organizada. Para ello se examina, previamente, la legislación nacional y comparada.

PALABRAS CLAVE: Criminalidad organizada - asociación ilícita - globalización - coautoría - orden público.

\section{TOWARDS CRIMINAL LIABILITY OF THE ORGANIZED CRIME. A PROPOSAL IN LEGE FERENDA MANNER}

ABSTRACT: Organized crime has become one of the criminal manifestations of the new era, marked by the globalization phenomenon. This can be seen through the various international instruments that have been approved in recent years. Even though the associative crimes are enshrined in penal codes since the nineteenth century, organized crime

Este Trabajo ha sido realizado dentro del marco del Proyecto Fondecyt $N^{\circ} 1130406$ titulado "La criminalidad organizada: examen desde una perspectiva jurídica y política" que el autor dirije como investigador responsable.

Fecha de recepción: 6 de marzo de 2014

Fecha de aceptación: 11 de agosto de 2014.

** Doctor en Derecho. Profesor Titular de Derecho Penal y Director del Centro de Estudios de Derecho Penal de la Universidad de Talca (CHILE). Correo electrónico: rcarnevali@utalca.cl 
would settle a specific embodiment of conspiracy which it would make itself obvious through its higher level of dangerousness. Hence, the need to develop a normative proposal that gathers the special devalue of this kind of behavior arises. In this context, this work aims at examining two subjects in particular. The first one aims at specifying the object of protection of associative crimes and the indictment criteria. The second issue is the development of criminal regulations concerning the organized crime. For that, the national and comparative legislation are previously examined.

KEY WORDS: Organized crime - illegal association - globalization conspiracy - public order.

\section{1) CONSIDERACIONES PREVIAS. UNA APROXIMACIÓN AL TEMA}

Si bien la presencia del delito de asociación ilícita en los ordenamientos jurídicos nacionales data de principios del siglo XIX, es posible observar que en el último tiempo las organizaciones criminales han adquirido particular relevancia. Incluso, se llega a aseverar que el paradigma del Derecho penal de la globalización -propio de nuestra época- es el delito económico, siendo una de sus modalidades la macrocriminalidad, expresada en la criminalidad organizada. Hoy es posible observar una evidente tendencia de orden legislativo a incrementar el recurso a esta figura distinguiendo, como se verá infra, entre lo que es asociación ilícita y la criminalidad organizada, en una relación de género a especie. Teniendo en consideración pues, que no solo se está lejos de su supresión, sino que, por el contrario, se valora este delito como una herramienta eficaz para enfrentar determinados fenómenos criminales, resulta fundamental establecer ciertos parámetros que lo legitimen ${ }^{2}$. Lo anterior se hace aún más inevitable dada sus peculiaridades, pues autoriza una intervención punitiva anticipada; es decir, el Estado puede actuar en la medida que se estime que la organización puede conformar una amenaza, aunque luego, aquello no se materialice en delitos concretos.

1 Silva Sánchez, Jesús M. (2011). La expansión del Derecho penal. Aspectos de la Política Criminal en las sociedades postindustriales. Montevideo: B de F, p. 106. Cabe señalar que la denominación criminalidad organizada y crimen organizado expresan el mismo fenómeno. En todo caso, la segunda noción es más bien propia del mundo anglosajón, organized crime. Así lo deja claro, Zúniga Rodríguez, Laura (2006). "Criminalidad organizada, Derecho penal y sociedad. Apuntes para el análisis”. En Sanz Mulas, Nieves (coord.). El desafío de la Criminalidad Organizada. Granada: Comares, p. 39.

2 Ziffer, Patricia (2008). "El delito de asociación ilícita frente al "Derecho penal de la expansión”. En Cancio Meliá, Manuel/Pozuelo Pérez, Laura (coord.). Política criminal en vanguardia. Cizur Menor: Thomson Civitas, p. 495. 
Justamente lo anterior pone en evidencia la necesidad de precisar el objeto de protección, que tradicionalmente se centra en determinados bienes jurídicos colectivos, ya sea, el orden público, la seguridad interior o la paz pública. Sin perjuicio de lo que se precisará más adelante, tales nociones suponen un riesgo cierto de que en pos de su resguardo, el Estado asuma políticas con fuertes rasgos intervencionistas ${ }^{3}$. Al respecto, no puede obviarse que estos delitos de algún modo rompen la lógica clásica acerca de la impunidad de los actos preparatorios ${ }^{4}$.

Amén de lo recién indicado, también se puede concordar que nociones como orden público o seguridad interior tampoco facilitan la tarea del intérprete, pues de suyo son ambiguas e imprecisas, cuestión que ya en el siglo XIX se ponía en evidencia cuando se iniciaban los procesos codificadores. Precisamente, esta suerte de incerteza en la comprensión de lo que se intentaba proteger, de algún modo permitía a los Estados que en ese entonces se estaban formando, cierta laxitud a la hora de recurrir al delito de asociación ilícita -asociación de malhechores en el Código francés de 1810 - con el propósito de reprimir todas aquellas agrupaciones que podían considerarse políticamente peligrosas 5 .

A pesar de esta vaguedad conceptual, la mayoría de los Códigos de la época no tuvieron reparos en introducir sendos títulos relativos a la protección del orden público, en los que se comprendían los más diversos delitos, sin mayor vinculación. Así, por ejemplo, en el Código penal francés de 1810 abarcaba dentro del mismo título, delitos cometidos por funcionarios públicos en ejercicio de sus funciones, desobediencia, vagancia, asociación de malhechores, entre otros. Lo mismo acontecía con el llamado Código Zanardelli de 1889 o anteriormente, con el Código penal toscano. Es así que Carrara apuntaba a destacar lo excesivamente difuso del término, en orden a que cualquier delito ofende el orden público, pues todo crimen perturba la tranquilidad pública, al afectar la opinión de

\footnotetext{
Así ya lo afirma, Moccia, Sergio (2003). El Derecho penal entre ser y valor. Traducción de Bonnano, Antonio. Montevideo: B de F, pp. 261 y ss.

Como lo resalta, Ziffer, (2008) 500.

Señala Sánchez García de la Paz, Isabel (2001). "Función político-criminal del delito de asociación para delinquir: desde el derecho penal político hasta la lucha contra el crimen organizado". En Arroyo Zapatero, Luis/Berdugo Gómez de la Torre, Ignacio (dir.). Homenaje al Dr. Marino Barbero Santos. In Memoriam. Vol II. Cuenca: Ediciones de la Universidad de Castilla-La Mancha/Ediciones Universidad de Salamanca, p. 649, que los siglos XVIII y XIX se caracterizan por su fuerte convulsión política y de agitaciones sociales, de manera que a través de estas figuras penales se perseguían también a los adversarios políticos. Téngase presente, que el Código penal español de 1848 castigaba a las sociedades secretas, comprendiéndolas dentro del título de los delitos contra la seguridad interior del Estado. Militello, Vincenzo (2004). "La pertenencia a una organización criminal como tipo penal modelo europeo". Persona y Derecho. $\mathrm{N}^{\circ}$ 51, p. 287 hace presente que el origen de estas figuras de remonta a la antigua association des malfaiteurs francesa.
} 
los ciudadanos acerca de su propia seguridad ${ }^{6}$. Dicho en otros términos, todos los delitos tienen un daño mediato, pues erosionan el orden o paz pública, es por ello que ciertos hechos se elevan al carácter de delito -trascienden la relación autor-víctima ${ }^{7}$ - . Pero distinto es, que el daño mediato sirva de criterio único para precisar los delitos. No se pueden confundir las funciones del daño mediato con las del daño inmediato, que solo afectan al individuo ${ }^{8}$.

Precisamente, y a fin de evitar ejercicios indebidos de la actividad punitiva, es que se hace indispensable establecer criterios que le den sentido y significado al delito que se examina, resolviéndose, entre otros aspectos, el bien jurídico protegido. Por de pronto, estimo que sí es legítimo que el ordenamiento penal se contemple un injusto penal que comprenda comportamientos propios del crimen organizado -según se verá, entendiéndolo como una modalidad específica de asociación ilícita- ${ }^{9}$. Y es que el desvalor implícito en estas figuras es mayor que aquel que puede apreciarse en otras actividades de carácter plural o conjunta -así, la coautoría-. La presencia de una estructura con grados de jerarquización, con cierta prolongación y estabilidad en el tiempo, dirigida a la consecución de ciertos propósitos, dispuesto en una especie de programa-generalmente de carácter lucrativo-, conlleva, por cierto, un riesgo mayor para ciertos bienes jurídicos. Basta tener en consideración los delitos en que se ven

6 Carrara, Francesco (1985). Programa de Derecho criminal. Parte General. vol. IV. Traducción de Ortega Torres, José y Guerrero, Jorge. Bogotá: Temis, \$1574, p. 352.

7 Como señalo en Carnevali, Raúl (2005) "Las políticas de orientación a la víctima examinadas a la luz del Derecho penal". Revista de Derecho de la Pontificia Universidad Católica de Valparaíso, XXVI, Semestre I, p. 38, el que se esté frente a un delito supone necesariamente una referencia a terceros, más allá de la víctima. El delito no es un conflicto de estructura dual, como sí lo son los conflictos propios del Derecho Civil. Las normas penales se dirigen a buscar un restablecimiento de la paz quebrantada por la comisión de un delito, por tanto, se pone de manifiesto que se trata de conflictos que tienen una trascendencia general y no disputas que solo interesan esencialmente a dos sujetos. Es esta la razón y no otra, por lo que se ha decidido enmarcar el conflicto dentro de la esfera del Derecho Penal.

8 Molinario, Alfredo (1949). El bien jurídico garantizado con la incriminación de los delitos contra el orden público o la paz pública. Montevideo: Impresora uruguaya, p. 30, cita al jurista italiano Puccioni quien al comentar los delitos contra el orden público en el Código toscano señala lo siguiente: "La rúbrica de este título tiene algo de genérico e indefinido que parece no convenir a una especie de familia o clase de delincuencias, puesto que contiene todas las que la ciencia ha adoptado y las que la humana maldad puede producir. Cualquier delito, en efecto, ofende al orden público ya directamente, porque aflige el cuerpo social o la majestad de las leyes creadas para la pública tutela o indirectamente, porque los dańos que ocasiona influyen en todos por la alarma que producen y porque, a través del perjuicio que experimenta la víctima, suscitan un temor que compromete la seguridad común".

9 Dando argumentos sobre la legitimidad, SÁnchez García de la PAZ, Isabel (2008). "Problemas de legitimidad de una respuesta excepcional frente a las organizaciones criminales". En Cancio Meliá, Manuel/Pozuelo Pérez, Laura (coord). Politica criminal en vanguardia. Cizur Menor: Thomson Civitas, pp. 453 y ss. Respecto al caso norteamericano, AbADInsky, Howard (2013). Organized Crime. $10^{\circ}$ ed. Belmont: Wadsworth, pp. 1 y ss.; Albanese, Jay S. (2011). Organized Crime in our times. $3^{\circ}$ ed. Burlington: Elsevier, pp. 181 y ss. 
involucradas las organizaciones criminales, como por ejemplo, los tráficos de drogas, de armas, de personas o el financiamiento del terrorismo.

En este sentido, hace ya un tiempo Lampe efectuó una interesante distinción entre diversos sistemas de injusto, que son relaciones entre individuos organizados hacia fines injustos. Por un lado, están los sistemas de injusto simple que se organizan hacia un fin común a través de la voluntad de los individuos en ellos contenidos. El ejemplo más notorio es la coautoría. Por otro lado, se está ante un sistema de injusto constituido, cuando se es más que la suma de las partes, adquiriendo su configuración duradera a través de una constitución o estatutos. Es aquí donde se sitúan las organizaciones criminales ${ }^{10}$.

Por otro lado, no puede dejarse de considerar los graves peligros que para el funcionamiento democrático de un Estado puede llegar a significar la criminalidad organizada ${ }^{11}$. En efecto, si bien tales organizaciones no pretenden alcanzar el poder político, sí se dirigen a controlarlo, como una especie de poder en la sombra. En este contexto, conforman una fuente de corrupción de funcionarios públicos con graves consecuencias para la legitimidad de las instituciones estatales, pues los ciudadanos van perdiendo la confianza, dando lugar a percepciones de inseguridad pública. Lo que sucede en varios países latinoamericanos es muestra evidente de lo que se quiere expresar ${ }^{12}$.

Asimismo, no puede perderse de vista, que las actividades desplegadas por estas organizaciones también afectan la economía ilícita, pues pretenden involucrarse -infiltrarse- en ella, como sucede con el lavado de

10 Lampe, Ernst-Joachim (2003). "Injusto del sistema y sistema de injusto". Traducción de Gómez-Jara, Carlos. En LAMPE, Ernst-Joachim. La dogmática jurídico-penal entre la ontología social y el funcionalismo. Lima: Grijley, p. 104 y ss. Sobre esta distinción, Mañalich, Juan Pablo (2011). "Organización delictiva. Bases para su elaboración dogmática en el derecho penal chileno". Revista Chilena de Derecho. Vol. 38 N² 2, pp. 279 y ss.

11 Laudati, Antonio (2003). "Criminalità organizzata e riciclaggio". En Patalano, Vincenzo (editor), Nuove strategie per la lotta al crimine organizzato transnazionale. Turín: Giappichelli, p. 217: "El crimen organizado constituye un peligro para las democracias modernas por la extraordinaria capacidad de acumular enormes riquezas y de contaminar y condicionar las instituciones"; SÁnchez García de la PAZ (2008) 456.

12 En dicha región se aprecia una permanente inestabilidad política, constantes casos de corrupción donde se ven involucrados, incluso, altos representantes del gobierno. Todo ello genera una pérdida de confianza por parte de la ciudadanía hacia las autoridades, pues en no pocos casos no son sancionados, percibiéndose una especie de cultura de la impunidad. Pues bien, si a la debilidad del Estado de Derecho se le agrega la perenne desigualdad social imperante, el escaso respeto por los derechos humanos, los espacios que se le ofrecen a grupos criminales organizados son enormes. $\mathrm{Y}$ es que las posibilidades de ser perseguidos y sancionados son mínimas, más aún si existe una suerte de connivencia entre estos grupos y la autoridad pública. Sobre el punto, Solís, Luis Guillermo/Rojas Aravena, Francisco (editores) (2008). Crimen organizado en América Latina y el Caribe, Santiago: Catalonia; ZúñIga RoDRÍGUez, Laura (2009). Criminalidad organizada y sistema de derecho penal. Contribución a la determinación del injusto penal de organización criminal. Granada: Comares, pp. 110-114. 
los dineros que provienen del tráfico de drogas ${ }^{13}$. Ello afecta gravemente las reglas del mercado y de la competencia.

Si bien existe un parecer mayoritario por entender la necesidad de disponer de normas específicas que recojan la especial gravedad de la criminalidad organizada, también es posible encontrar discursos que apuntan a los peligros que representan ciertas manifestaciones más bien propias de un Derecho penal de corte autoritario ${ }^{14}$. Precisamente, una de estas expresiones estaría representada por los llamados delitos asociativos. Entre los autores que exponen esta línea se halla Ferrajoli, para quien es suficiente abordar este fenómeno a través de los delitos-objeto de la asociación ${ }^{15}$. En este sentido expresa: "En el primer aspecto, toda penalización a título de delito "político" termina en la tutela excesivamente anticipada de figuras de peligro abstracto o presunto en contradicción con el principio de lesividad o, incluso, como ocurre en los delitos asociativos, en una duplicación de la responsabilidad penal ya afirmada en los delitos comunes, como la tenencia de armas, los actos de violencia consumados o intentados o el concurso en su comisión o preparación" ${ }^{16}$. Empero, tal como en su momento Marinucci y Dolcini señalaron, no son poco los casos en que la organización ni siquiera requiere cometer delitos, pues

13 Entre otros, Fernández Cruz, José Ángel (2002). "La 'empresa criminal': Los 'delitos de comercio' ilícito como factor de aparición del fenómeno del 'blanqueo de capitales". Revista de Estudios Criminológicos y Penitenciarios, 5, p. 90; Szczaranski, Clara (2000). "El Consejo de Defensa del Estado y el control de la criminalidad organizada y del lavado de dinero". En Politoff, Sergio/ Matus, Jean Pierre (coord.). Gran criminalidad organizada y tráfico ilícito de estupefacientes. Santiago: ConoSur, pp. 48-52. Castaldo, Andrea/Naddeo, Marco (2010). Il denaro sporco. Prevenzione e repressione nella lotta al riciclaggio, Padua: Cedam; ZÚNIGA (2009) 128.

14 En esta línea, Moccia, Sergio (1999). "Prospettive non 'emergenziali' di controllo dei fatti di criminalità organizzata. Aspetti dommatici e di politica criminale". En Moccia, Sergio (ed.), Criminalità organizzata e risposte ordinamentali, Nápoles: Edizioni Scientifiche Italiane, pp. 149 y ss.

15 Ferrajoli, Luigi (1995). Derecho y razón. Teoría del garantismo penal. Traducción de Andrés Ibánez, Perfecto et al., Madrid: Trotta, pp. 832 y ss.

16 Ferrajoli (1995) 832. En p. 833: "La misma argumentación vale también, evidentemente, para las demás figuras de delitos y de delincuentes especiales, igualmente reconducibles a fenomenologías criminales globales -el bandidaje, la mafia, la camorra- $y$, por lo demás, ni siquiera caracterizadas por una especificidad en abstracto de los bienes jurídicos protegidos. También la expulsión del derecho penal de tales tipologías de autor responde a una garantía de seguridad contra las perversiones sustancialistas e inquisitivas, además de a una elemental exigencia de igualdad. Se trata, en efecto, de figuras informadas por el paradigma constitutivo $y$, por tanto, contrarias al carácter exclusivamente regulativo que deben tener las normas penales. Naturalmente, también en estos casos la naturaleza mafiosa o camorrista de un delito puede considerarse como un rasgo particularmente grave en el momento de la comprensión y la valoración equitativa del hecho. Pero ni siquiera en estos casos se justifican figuras de delito especial, como lo es típicamente, en nuestro ordenamiento, la asociación de tipo mafioso prevista por el art. 416 bis del código penal en lugar de la normal avocación para delinquir. También la mafia, como el terrorismo, debe y puede ser afrontada con los medios penales ordinarios". 
basta su presencia para causar la intimidación necesaria que les permita la consecución de sus objetivos ${ }^{17}$. Parece pues, que esperar que tales delitosobjetos de la asociación se realicen supone, de forma injustificada, renunciar a importantes herramientas que permiten enfrentar estas formas de criminalidad organizada ${ }^{18}$.

Ahora bien, que se legitime tal adelantamiento a fin de punir estos comportamientos impone, por cierto, la tarea de fundamentar cuándo pueden estimarse peligrosos, esto es, cuándo el formar parte de una agrupación puede considerarse disvalioso ${ }^{19}$. No hay duda que un recurso criminalizador indebido puede dar pábulo a una fuerte intervención en la esfera privada de las personas, castigando actos que carecen del mínimo componente de peligrosidad que justifican la intervención punitiva.

A continuación, se pretende examinar y someter a la discusión dos materias en particular. La primera dirigida a precisar el objeto de protección de los delitos asociativos, entendiendo que se enfrentan dos grandes posiciones, a saber, que se está frente a un bien jurídico de carácter supraindividual o que la función tuitiva se dirige a aquellos bienes que se comprenden dentro de la esfera de la organización. El segundo tema apunta a entender que la criminalidad organizada constituiría una modalidad específica de asociación ilícita, lo que hace necesario elaborar una propuesta normativa que recoja el especial desvalor de esta clase de comportamientos. Es decir, es indispensable disponer de normas que precisen los elementos que distinguen a una organización criminal de otro tipo de agrupaciones o asociaciones.

Antes de exponer estos puntos, quisiera dedicar las siguientes líneas a dar cuenta de aquellos elementos que distinguen a la criminalidad organizada y por qué, según mi parecer, se debe prestar especial atención a este fenómeno y que justificaría su expresión en el orden normativo. Precisamente, su análisis desde diversas perspectivas -entre otras, culturales, sociales y político criminal- permiten una mejor comprensión.

17 Marinucci, Giorgio/Dolcini, Emilio (1999). “Diritto penale ‘minimo' e nuove forme di criminalità". Rivista italiana di diritto e procedura penale, p. 817 (Existen dos traducciones al español realizadas por mí en Revista de derecho penal y criminología, nº 9, 2002, p. 147 y ss. y Revista de Derecho de la Universidad Católica del Norte (sede Coquimbo), N 8, 2001, pp. 231 y ss.).

18 Marinucci/Dolcini (1999) 817. La respuesta a este artículo en Ferrajoli, Luigi (2000). "Sul diritto penale minimo (risposta a Giorgio Marinucci e a Emilio Dolcini)". Foro italiano, Parte Quinta, p. 126 y ss.; Cancio Meliá, Manuel (2008). "El injusto de los delitos de organización: peligro y significado”. En Cancio Meliá, Manuel/Pozuelo Pérez, Laura (coord). Politica criminal en vanguardia. Cizur Menor: Thomson Civitas, p. 387, también da cuenta que van perdiendo fuerza posturas como las de Ferrajoli. Así también lo pone de manifiesto, Ziffer, (2008) 500. 


\section{2) EL CRIMEN ORGANIZADO COMO EXPRESIÓN DE CRIMINALIDAD DE LOS NUEVOS TIEMPOS. LA GLOBALIZACIÓN}

Aun cuando el delito de asociación ilícita, en su noción moderna, comienza a precisarse en los Códigos penales decimonónicos, como el francés -art. 265 y ss.-, el toscano de 1854 -art. 207 y ss. ${ }^{20}$-, o el español de $1848 / 50$-art. 211 y ss.-, ya en el derecho romano se lo trataba. En efecto, con el nombre de conventiculo se aludía a la comunidad de sujetos dirigida a atacar al príncipe o al Estado ${ }^{21}$. Con la bula del papa Sixto V -siglo XVI- se empleó dicha expresión para referirse a las bandas que atacaban a las personas y a la propiedad, en la medida que se asociaban con malos fines y con armas ${ }^{22}$. Fueron justamente, los prácticos italianos los que expandieron el concepto para referirse a aquellas agrupaciones armadas que cometían saqueos u otros delitos.

No se pretende realizar un examen histórico de la figura, pero sí poner en evidencia que no se trata de un fenómeno reciente ${ }^{23}$. En todo caso, sí llama la atención cómo en el último tiempo el crimen organizado ha acaparado la atención, motivando la preocupación de organismos internacionales y de este modo a los ordenamientos nacionales. En efecto, ya es común afirmar que la criminalidad organizada conforma una de las expresiones delictuales que surgen con mayor fuerza dentro de la esfera de la globalización ${ }^{24}$. Es en este contexto, de menores restricciones de orden

20 El texto del Código penal de la Toscana, se puede conocer en Carrara (1985) vol. X, 205 y ss.

21 Carrara (1985) vol. VI, $\$ 2094,116$. También se refería a las comunidades religiosas que se reunían para exponer sus propuestas religiosas.

22 Carrara (1985) vol. VI, \$ 2094, 116; Jiménez de Asúa, Luis (1970). Tratado de Derecho penal. Tomo VII. Buenos Aires: Losada, pp. 370-371.

23 Cancio Meliá (2008) p. 394. Interesante resulta conocer la historia de la mafia italiana y cómo se encuentra enraizada en la cultura de ciertas zonas del sur italiano. Al respecto, Romano, Salvatore (1966). Storia della mafia. Verona: Mondadori; Block, Antón (1974). The Mafia of a Sicilian Village 1860-1960, Oxford: Basil Blackwell. Sobre el desarrollo de la camorra napolitana, Di Fiore, Gigi (2005). La camorra e le sue storie. Turín: Utet; Rovito, Pier Luigi (1999). "Mentalità emergenziale e crimine organizzato: profili storici". En MocCIA, Sergio (ed.). Criminalità organizzata e risposte ordinamentali. Nápoles: Edizioni Scientifiche Italiane, p. 11 y ss. Sobre la expansión del crimen organizado en los Estados Unidos, Marine, Frank (2006). "The effects of organized crime on legitimate businesses". Journal of Financial Crime. Vol. $13 \mathrm{~N}^{\circ}$ 2, pp. 215 y ss. En pp. 226 y ss. se refiere al caso ruso tras el colapso de la Unión Soviética; Abadinsky, (2013) 19 y s.

24 Carnevali, Raúl (2010). "La criminalidad organizada. Una aproximación al derecho penal italiano, en particular la responsabilidad de las personas jurídicas y la confiscación”. Ius et Praxis, año 16, № 2, p. 275; Villacampa Estiarte, Carolina (2012). "Trata de seres humanos y delincuencia organizada". In dret. $\mathrm{N}^{\circ}$ 1, p. 9; Callegari, André Luis (2010). "Crimen organizado: concepto y posibilidad de tipificación delante del concepto de la expansión del derecho penal". Revista Derecho penal y criminología. Vol. XXXI, N 91, p. 27; GILligan, George (2007). "Business, risk and organized crime". Journal of Financial Crime. Vol. $14 \mathrm{~N}^{\circ}$ 2, p. 109; Shelley, Louise (1995). "Transnational organized crime: an imminent threat to the nation-state?”. Journal of International Affairs. Vol. 48, N², pp. 2 y ss. (fuente: vlex). 
comercial y de mayor apertura de los mercados, en donde los factores productivos pueden circular con mayor libertad, es que se brindan mayores márgenes de actuación al crimen organizado. Y es que al flexibilizarse los controles estatales para la libre circulación de estos productos, a saber, capitales, servicios, mercancías y personas, las organizaciones criminales pueden actuar con mayor libertad, sobre todo respecto de aquellas asociaciones que presentan un carácter transnacional. Unido a lo anterior, no debe dejarse de lado el desarrollo tecnológico que facilita particularmente la comisión de delitos 25 .

Pues bien, lo expuesto nos afirma un elemento que es esencial de la criminalidad organizada y que, precisamente, determina las medidas que se pueden instaurar para poder enfrentarlas: su fin lucrativo. Lo que motiva su conformación es la consecución de ganancias económicas ${ }^{26}$.

Lo recién indicado nos pone en evidencia una particularidad de esta clase de asociaciones, a saber, que tienen un propósito eminentemente económico; es decir, que su motivación esencial, lo que determina especialmente su conformación, es la consecución del lucro. Es cierto, como se verá más adelante, que existen organizaciones criminales que se estructuran para perseguir otros fines, como las terroristas, pero las que generan mayor atención por su impacto en la sociedad, son, justamente, las primeras. Ya se mencionó supra la incidencia que estas organizaciones tienen para la estabilidad democrática de los Estados. Basta tener presente lo que acontece en México, donde hay manifestaciones claras de un vacío de Estado, con la conformación de grupos de autodefensa para enfrentarse a los carteles de drogas ${ }^{27}$. Unido a ello están los peligros que representan estas organizaciones para la transparencia de las economías nacionales, pues lo que pretenden es, precisamente, infiltrarse en el sistema económico lícito a fin de blanquear sus ganancias, alterando gravemente las reglas del mercado ${ }^{28}$. Es por ello que uno de los principales instrumentos para enfrentarlas es el comiso, ya que apunta a limitarlas e incapacitarlas financieramente ${ }^{29}$.

25 El artículo 570 bis del Código penal español agrava las penas cuando se trata de organizaciones criminales que se valen de medios tecnológicos que facilitan la comisión de los delitos. Al respecto, Callegari (2010) 27; Laudati (2003) 219; Di Nicola, Andrea (2002). "La criminalitá economica organizzata: implicazioni di politica penale". Rivista Trimestrale di Diritto Penale dell'Economia, p. 279.

26 Castaldo, Andrea (2005). "La naturaleza económica de la criminalidad organizada". En YACOBUCCI, Guillermo (coord.). El crimen organizado. Desafíos y perspectivas en el marco de la globalización. Buenos Aires: Abaco de Roberto Depalma, pp. 271 y ss.; Silva Sánchez, Jesús M. (2011) 85; ZúNíga (2009) 128.

27 Es lo que sucede en Michoacán donde grupos de autodefensa se enfrentan al Cartel de los Caballeros Templarios. El Mercurio, 14 de enero de 2014, p. A4.

28 Di Nicola (2002) 276.

29 Debe tenerse presente que diversos instrumentos internacionales disponen el comiso como una instrumento eficaz para enfrentar la criminalidad organizada. Es el caso, de la Conven- 
En este sentido, resulta particularmente ilustrativo lo que expone Ferrajoli para destacar el significado de la globalización y los cambios para entender la cuestión crimina ${ }^{\beta 0}$. En efecto, señala que la forma de criminalidad que constituye una amenaza más grave para los derechos, la democracia y la paz es la criminalidad del poder, la que se manifestaría de tres formas: la criminalidad organizada; la de los crimenes de los grandes grupos económicos, y la de los crímenes de los poderes públicos. Para Ferrajoli, no se trata de fenómenos que deban entenderse por separado ni tampoco son diversos entre sí, sino que pueden actuar todos coludidos; es decir, se puede estar ante poderes criminales, económicos y políticos ${ }^{31}$. La primera de estas formas, a saber, el crimen organizado ha ido adquiriendo un particular desarrollo, constituyendo hoy por hoy en uno de los sectores más florecientes y rentables de la economía internacional ${ }^{32}$.

En lo que se refiere a las otras dos formas de criminalidad de poder, Ferrajoli afirma que la constituida por los grandes grupos económicos se manifiesta en la corrupción, apropiación de recursos naturales y devastación del medio ambiente 33 . Precisamente, es en esta esfera donde se aprecian más nítidamente los efectos de la globalización, por la ausencia o vacío de Derecho público, que se manifiesta en el desarrollo de poderes desregulados que tienen como único propósito el beneficio y la autoacumulación.

ción $O C D E$ sobre la lucha a la corrupción de los funcionarios públicos extranjeros en las operaciones económicas internacionales de 1997 en su art. 3 se establece que: "3. Cada Parte tomará las medidas necesarias para que el instrumento y el producto del cohecho de un servidor público extranjero o activos de un valor equivalente al de ese producto puedan ser objeto de embargo y decomiso o sean aplicables sanciones monetarias de efectos comparables". En el caso de la Convención de Palermo, dispone el comiso en los art. 12, 13 y 14. En la esfera de la Unión Europea se puede citar la Decisión Marco 2005/212/JAI que se refiere al decomiso de los productos, instrumentos y bienes relacionados con el delito, resaltando en: "7. La motivación principal de la delincuencia organizada es la obtención de beneficios económicos. Por consiguiente, todo intento de prevenir y combatir esta delincuencia debe centrarse, para ser eficaz, en el seguimiento, el embargo preventivo, la incautación y el decomiso de los productos del delito. No basta simplemente con garantizar el reconocimiento mutuo dentro de la Unión Europea de medidas legales temporales como el embargo preventivo y la incautación; el control efectivo de la delincuencia económica también exige el reconocimiento mutuo de las resoluciones de decomiso de los productos del delito". Al respecto, Carnevali (2010) 307 y ss.; Mangione, Angelo (2008). " "Law \& Economics" e diritto penale: paradigma a confronto nell'analisi delle politiche di contrasto alla criminalità organizzata". En MAUGERI, Anna Maria (ed.), Le sanzioni patrimoniali come moderno strumento di lotta contro il crimime: reciproco riconoscimento e prospettive di armonizzazione. Milán: Giuffrè, pp. 147 y ss.

30 Ferrajoli, Luigi (2009). "Criminalidad y globalización”. En Carbonell, Miguel/ VásQuez, Rodolfo (Comp.), Globalización y Derecho. Quito: Ministerio de Justicia y Derechos Humanos, pp. 147 y ss.

31 Ferrajoli (2009) 148.

32 Ferrajoli (2009) 148, destaca que en la criminalidad organizada se presenta una estratificación de clase, dado que la pequeña criminalidad es, a su vez, explotada por la gran criminalidad compuesta por grupos dirigentes. FerRAJOLI (2009) 149. 
Conforme a lo expuesto, se puede señalar que los contornos para trazar una distinción entre esta forma de criminalidad y la primera -la criminal de tipo mafioso- es ciertamente impreciso. En efecto, los grupos económicos también se aprovechan de las debilidades institucionales y pobreza de algunos Estados para actuar y obtener el mayor rédito a sus inversiones, desplegando sus actividades con cierta impunidad, sin preocuparse especialmente por las consecuencias, ya sea en la esfera ambiental o por las condiciones de trabajo de la población.

En cuanto a la tercera expresión de criminalidad del poder, referida a la acción de los poderes públicos, se manifiesta, según Ferrajoli, en formas de corrupción y de apropiación de la cosa pública, poniendo de manifiesto una clara desviación de orden institucional. Se exterioriza a través de una evidente connivencia con los grupos económicos, pues estos últimos se valen del aparato público para la consecución de sus objetivos - una especie de apoderamiento privado de la cosa pública- ${ }^{34}$.

Es por ello que se habla de una captura del Estado, en el entendido de que individuos, empresas o grupos al aprovecharse de sus contactos o asociaciones ilícitas obtienen ganancias o facilitan actuaciones que a otros particulares no les serían permitidas. Tiene lugar una colusión particular entre lo público -ya sea funcionarios, legisladores o políticos- y los privados en que se definen políticas públicas, se obtienen ventajas contractuales, favoreciendo de este modo solo a unos pocos, alterando las reglas de igualdad entre quienes intervienen en una determina actividad ${ }^{35}$.

Siguiendo una línea similar a la expuesta por Ferrajoli, Lampe distingue tres formas típicas al referirse a los sistemas de injusto constituido -sistema que se explicó supra-: a) las agrupaciones orientadas criminalmente; b) las empresas económicas con tendencia criminal, y c) las estructuras estatales pervertidas criminalmente. Respecto de las agrupaciones orientadas criminalmente su finalidad o actividad se dirige a cometer delitos. En el caso de las empresas económicas con tendencia criminal, el injusto penal no es esencial, pues las infracciones dolosas o culposas que tienen lugar dentro de las empresas no están dentro de su finalidad. Por último, en el caso de las estructuras estatales pervertidas criminalmente, aun cuando

\footnotetext{
Ferrajoli (2009) 149-150.

Así lo exponen, Rodríguez Collao, Luis/ Ossandón Widow, Magdalena (2008). Delitos contra la función pública. 2a ed. Santiago: Editorial Jurídica de Chile, p. 58-59, quienes afirman que la corrupción pública modifica las reglas del juego, al dar lugar a una desigualdad oculta y mecanismos que son perversos para el desarrollo. En el caso italiano, esta captura se puede apreciar en los contratos que organizaciones mafiosas han celebrado con la administración pública para el tratamiento de los residuos tóxicos -la llamada Ecomafia-. Sobre el punto, Plantamura, Vito (2007). "Ecomafia, reati associativi e diritto penale dell'economia". Rivista Trimestrale di Diritto Penale dell'Economia, pp. 73 y ss.; Lo Monte, Elio (2003). "Ecomafia: il controllo penale tra simbolicità ed effettività". En Patalano, Vincenzo (ed.), Nuove strategie per la lotta al crimine organizzato transnazionale. Turín: Giappichelli, pp. 235 y ss.
} 
no hay infracciones a leyes penales -como en los dos casos anteriores-, su injusto radica en la ilegitimidad de sus leyes abstractas o de sus medidas soberanas concretas ${ }^{36}$.

Sin perjuicio de todo lo expuesto, siempre deben tenerse en consideración elementos de orden social y cultural para poder comprender delitos de esta naturaleza. Y es que se presentan ciertas condicionantes que facilitan la conformación de agrupaciones criminales. En efecto, aun cuando se ha transformado en un lugar común hablar de la pobreza y la exclusión para explicar la criminalidad, no por ello pierden fuerza como argumento a considerar. Justamente, la propia Convención de Palermo lo destaca con especial ahínco, instando a los Estados a disponer de medidas para enfrentarlas ${ }^{37}$. Asimismo y como se ha resaltado anteriormente, la criminalidad organizada se despliega con mayor éxito en aquellos países donde sus bases institucionales son más febles y su desarrollo democrático no está especialmente sustentado como para evitar la corrupción de sus funcionarios y la convivencia con agrupaciones criminales ${ }^{38}$. Lamentablemente, nuestro continente es un ejemplo de los riesgos que tienen lugar y de cómo la inestabilidad de los organismos políticos, generan frecuentes episodios de corrupción funcionarial, dando lugar a una sensación de inseguridad en la ciudadanía, por la pérdida en la confianza en sus instituciones. En consecuencia, si a la perenne desigualdad social que domina en buena parte de los países americanos -y de naciones de otros continentes, por cierto-, se une la carencia de sustento democrático y de una sólida defensa y respeto a los derechos humanos, las condiciones para la presencia y desarrollo de las asociaciones criminales son evidentes ${ }^{39}$.

36 Lampe (2003) 127 y ss

37 Artículo 15. 3 del Protocolo contra el tráfico ilícito de migrantes por tierra, mar y aire, que complementa la Convención de las Naciones Unidas contra la delincuencia organizada transnacional: "Cada Estado Parte promoverá o reforzará, según proceda, los programas y la cooperación para el desarrollo en los planos nacional, regional e internacional, teniendo en cuenta las realidades socioeconómicas de la migración y prestando especial atención a las zonas económica y socialmente deprimidas, a fin de combatir las causas socioeconómicas fundamentales del tráfico ilícito de migrantes, como la pobreza y el subdesarrollo”. Artículo 9. 4 del Protocolo para prevenir, reprimir y sancionar la trata de personas, especialmente mujeres y niños de la misma Convención: "Los Estados Parte adoptarán medidas o reforzarán las ya existentes recurriendo en particular a la cooperación bilateral o multilateral, a fin de mitigar factores como la pobreza, el subdesarrollo y la falta de oportunidades equitativas que hacen a las personas, especialmente las mujeres y los niños, vulnerables a la trata”. co (2006). El crimen organizado internacional: una grave amenaza a la democracia en América Latina y el Caribe. San José de Costa Rica: Flacso. ZúÑIGA (2009) 110-114. 


\section{3) LA CRIMINALIDAD ORGANIZADA: ¿SE PUEDE ENTENDER COMO UNA ESPECIFICIDAD DENTRO DE LA ASOCIACIÓN ILÍCITA? HACIA UN INJUSTO PENAL PROPIO}

En los últimos veinte años se va generando un conjunto de normas de carácter internacional que van dando cuenta del interés que produce la criminalidad organizada y la necesidad de tratamiento punitivo. En este contexto destaca, en el seno de las Naciones Unidas, el Plan Mundial de acción de Nápoles contra la delincuencia organizada transnacional de 1994, aprobado más tarde por la Asamblea General de las Naciones Unidas el 23 de diciembre de $1994^{40}$. Con posterioridad, en 2000 se aprobó el documento más importante sobre la materia, la Convención de Palermo que, entre otras disposiciones, define qué debe entenderse por grupo organizado ${ }^{41}$. El artículo 2 señala: "grupo estructurado de tres o más personas que exista durante cierto tiempo y que actúe concertadamente con el propósito de cometer uno o más delitos graves o delitos tipificados con arreglo a la presente Convención con miras a obtener, directa o indirectamente, un beneficio económico u otro beneficio de orden material'42.

En el ámbito europeo, también es posible encontrar disposiciones relativas a la criminalidad organizada, las que han motivado cambios legislativos en los países que forman parte de la Unión Europea (UE). Son estas normas de la UE las que han servido de basamento para algunas legislaciones europeas, las que serán revisadas más adelante. Ya en el Tratado de Ámsterdam, de fines de los noventa, se hacía referencia a la crimi-

40 Michelini, Gualtiero/Polimeni, Gioacchino (2007). "Il fenomeno del crimine transnazionale e la Convenzione delle Nazione Unite contro il crimine organizzato transnazionale”. En Rosı, Elisabetta (ed.), Criminalità organizzata transnazionale e sistema penale italiano. Milán: Ipsoa, pp. 8 y ss.; NunzI, Alfredo (2005). "La Convenzione delle Nazioni Unite contro la criminalità organizzata transnazionale”. En BAssiouni, Cherif M. (ed.), La cooperazione internazionale per la prevenzione e la repressione della criminalitá organizata e del terrorismo. Milán: Giuffrè, pp. 213 y ss.; ZúńIga (2009) 48 y ss.; Shelley (1995) 1 y ss.

41 Acerca de la Convención de Palermo, entre otros, Faraldo Cavana, Patricia (2012). Asociaciones ilícitas y organizaciones criminales en el Código penal español. Valencia: Tirant lo Blanch, pp. 37 y ss.; Pérez Cepeda, Ana (2004). Globalización, tráfico internacional ilícito de personas y derecho penal. Granada: Ed. Comares, pp. 63 y ss.; Zúñiga (2009) 49-50; BetTi, Stefano (2003). "New prospects for inter-state co-operation in criminal matters: The Palermo Convention". International Criminal Law Review, 3, p. 151; Orlova, Alexandra (2005). "'Umbrellas' or 'building blocks'? Defining international terrorism and transnational organized crime in international law”. Houston Journal of International Law. Vol. 27, $\mathrm{N}^{\circ} 2$, pp. 9 y ss. (fuente: vlex); Rosi, Elisabetta (ed.) (2007). Criminalità organizzata transnazionale e sistema penale italiano. Milán: Ipsoa; cfr. además, Nunzi (2005) 213 y ss.; Militello, Vincenzo (2005). "Le strategie di contrasto della criminalità organizzata transnazionale tra esigenze di politica criminale e tutela dei diritti umani”. En PArano, Carola/ Centonze, Alessandro (ed.), L'attività di contrasto alla criminalità organizzata. Milán: Giuffrè, pp. 249 y ss.; Callegari (2010) 34-35.

42 El Estado chileno a través del Decreto 342 de 2004 promulgó la Convención de Palermo y sus protocolos sobre trata de personas y tráfico ilícito de migrantes. 
nalidad organizada y la necesidad de establecer en este contexto acciones comunes. Más tarde se acordó la Decisión Marco 2008/841/JAI sobre lucha contra la criminalidad organizada dispuesta para lograr una adecuada armonización de las legislaciones de los Estados miembros ${ }^{43}$.

No se puede negar que se presentan particulares dificultades para delimitar un concepto de criminalidad organizada. Sin embargo, la determinación de sus elementos esenciales, como los indicados en la Convención de Palermo, facilita la armonización de las legislaciones nacionales, que es, justamente, uno de los caminos más eficaces para poder enfrentar la criminalidad organizada, sobre todo, considerando que en algunos casos tiene un carácter transnacional.

Hay quienes podrían pensar que sus presupuestos más elementales también pueden encontrarse en el delito de asociación ilícita, lo que haría innecesario un tratamiento particular. Con todo, existen diferencias y por tanto, no deben confundirse. La mayor peligrosidad que representan algunas organizaciones justifica la determinación de particulares medidas preventivas y sancionatorias. Justamente, uno de los objetivos perseguidos en este trabajo -que se abordará infra- se dirige a construir un injusto penal propio que recoja los presupuestos que son esenciales en la criminalidad organizada. Como afirma Barazzetta, respecto del delito de asociación de tipo mafioso, que contempla el artículo 416 bis del Código penal italiano, sus trazados particulares de incriminación persiguen claros objetivos de orden político criminal, dada su especial peligrosidad, lo que impone contemplar medidas de prevención particulares, que la distinguen de la asociación para delinquir del artículo $416^{44}$.

Según mi entender, la criminalidad organizada conformaría una modalidad especifica de la asociación ilícita. Es cierto que compartirían presupuestos similares, como son la concurrencia de una organización que da cuenta una cierta jerarquía que permite apreciar distribución de funciones, como así también que se observa una estabilidad temporal o permanencia que denota una proyección en el tiempo -que la distingue de la

43 Téngase presente también la Acción Común 1998/733/JAI para la tipificación penal de la participación en una organización delictiva. Así también, aunque relacionadas con el terrorismo, la Decisión Marco 2002/475/JAI, luego modificada por la Decisión Marco 2008/919/JAI. Sobre la materia, Peccioli, Annamaria (2005). Unione Europea e criminalità transnazionale. Turín: Giappichelli, pp. 131 y ss.; Salazar, Lorenzo (2005). "Misure di contrasto alla criminalità organizzata elaborate dall'Unione Europea”. En BAssiouni, Cherif M. (ed.), La cooperazione internazionale per la prevenzione e la repressione della criminalitá organizata e del terrorismo. Milán: Giuffrè, pp.128 y ss.; Fornasari, Gabriele (2002). "Le strategie di contrasto alla criminalità orgnizzata: aspetti comparatistici nell'esperienza europeo-continentale”. En Fornasari, Gabriele (ed.). Le strategie di contrasto alla criminalità orgnizzata nella prospettiva di diritto comparato. Padua: Cedam, pp. 173 y ss.; FAraldo CaVANA (2012) 47 y ss.

44 Barazzetta, Aurelio (2006). “Art. 416 bis”. En Marinucci, Giorgio/Dolcini, Emilio (dir.), Codice Penale commentato, $2^{\circ}$ ed. Milán: Ipsoa, pp. 3078 y ss. 
coautoría, por ejemplo- ${ }^{45}$. No obstante, en los supuestos de criminalidad organizada se aprecia además la concurrencia de determinadas actividades que forman parte de su programa delictivo y que pone de manifiesto una especial peligrosidad, que hace necesaria una tipificación particular, tal como se puede observar en el caso espańol e italiano. Precisamente, cuando fundamente mi propuesta normativa me haré cargo de estas aseveraciones.

Por otro lado, considerando que la regla general de estas estructuras criminales se dirige, fundamentalmente, a la consecución de fines de orden lucrativo, es esencial disponer de ciertos elementos de juicio que permitan diferenciar estas organizaciones de aquellas cuyos objetivos son diversos al económico. El caso más paradigmático, sin duda, es el terrorismo: muchos de estos grupos se construyen sobre la base de fines ideológicos, políticos o incluso religiosos.

La pregunta es muy simple: cómo podemos distinguir a una organización criminal -la mafia italiana, por citar un ejemplo-, de los grupos terroristas que presentan una estructura asociativa -así, la ETA española o las Brigadas Rojas en Italia-. Si bien ambos recurren a métodos similares, como la violencia o la extorsión, se presentan ciertas diferencias relevantes.

Por cierto, la tarea no parece en principio sencilla, pues la línea divisoria entre ambas expresiones criminales puede llegar a ser porosa. Por de pronto, los métodos empleados para implementar sus actividades pueden ser semejantes ${ }^{46}$. Unido a ello, en no pocos casos las estructuras terroristas se financian a través de las actividades del crimen organizado, de manera que se sirven mutuamente. Es lo que acontece entre organizaciones terroristas y carteles de la droga, en que las primeras suministran armas, apoyo logístico y libertad de movimiento, y las segundas, los recursos financieros a través de lavado y transferencias ilícitas -es lo que ha sucedido en Colombia con las FARC y los carteles de drogas- ${ }^{47}$. Es más, tampoco puede sorprender que organizaciones que comenzaron siendo terroristas, motivadas por razones ideológicas, devienen en simples organizaciones criminales fundadas en consideraciones económicas. Por otra parte, algunos estudios de seguridad se dirigen a estimar que ambos fenómenos deben ser tratados con similar rigor, sobre todo a partir de los ataques del 11 de septiembre de 2001, pues, como se señaló, se está produciendo una colaboración mutua ${ }^{48}$. Además, si se quiere ser eficiente en la lucha con-

45 En otro trabajo examiné con mayor detalle los presupuestos que caracterizan a una organización criminal, Carnevali (2010) 282 y ss.

46 Villegas Díaz, Myrna (2006). "Los delitos de terrorismo en el Anteproyecto de Código Penal”. Politica Criminal, $\mathrm{N}^{\circ} 2$, A3, pp. 18 y ss.

47 Abadinsky (2013) 16; Hardouin, Patrick (2009). "Bank governance and public-private partnership in preventing and confronting organized crime, corruption and terrorism financing". Journal of financial crime. Vol. $16 \mathrm{~N}^{\circ} 3$, p. 206.

48 Perri, Frank S./Brody, Richard G. (2011). "The dark triad: organized crime, terror and fraud". Journal of Money Laundering Control. Vol 14, N 1, p. 44. 
tra el terrorismo, no se pueden dejar de lado las fuentes de financiamiento que provee el crimen organizado -como señaló un jefe mafioso: "La mafia ayudará a quien puede pagar"- ${ }^{49}$. En este contexto, no se puede obviar que ambas organizaciones están aprovechando "muy eficazmente" las ventajas que ofrece una economía globalizada ${ }^{50}$.

Sin perjuicio de lo anterior, es importante sí disponer de ciertos elementos de juicio para distinguir ambos supuestos, sobre todo a la hora de resolver qué figura penal es la aplicable en la especie. Es evidente que ambas tienen un desvalor diverso, mayor en el caso del terrorismo, pues la comisión de los delitos que cometen persiguen, en definitiva, la coacción de los gobiernos y su capacidad decisional, alterando así, las reglas democráticas $^{51}$. En cambio, tratándose de la criminalidad organizada no hay un propósito subversivo, ni pretenden cuestionar los mecanismos políticos de tomas de decisión por parte del Estado, aun cuando sí quieren actuar al margen de sus reglas a fin de adquirir poder económico ${ }^{52}$. Por el contrario, su eficacia radica en actuar en la sombra. Por ello, uno de sus medios más frecuentes para obtener sus objetivos es la corrupción de funcionarios públicos. Por cierto, el querer realizar sus actividades de manera "desapercibida" no impide que bajo determinadas circunstancias cometan delitos violentos, como homicidios contra agentes del Estado. Sin embargo, no se pretende con ello un cauce político, sino más bien imponer ciertas normas de actuación dentro de un contexto, en donde las formas democráticas se mantienen ${ }^{53}$. Que así sea, se debe a una razón, suficientemente destacada y que es de la esencia del crimen organizado: el lucro de carácter ilícito.

\section{4) OBJETO DE PROTECCIÓN EN LOS DELITOS DE ORGANIZACIÓN}

\section{1) CUESTIONES PRELIMINARES}

Como se enunció al inicio de este trabajo, es preciso pronunciarse acerca de la función tuitiva de los delitos objeto de examen, lo que permi-

Perri/Brody (2011) 48.

Perri/Brody (2011) 46.

Llobet Anglí, Mariona (2008). Terrorismo y "guerra" contra el terror: límites de su punición en un Estado democrático. Tesis doctoral, Universidad Pompeu Fabra, Barcelona, pp. 37-38; Cancio Melí́, Manuel (2010). Los delitos de terrorismo: estructura típica e injusto. Madrid: Reus, pp. 154 y ss.; González Cussac, José Luis (2006). "El Derecho penal frente al terrorismo. Cuestiones y perspectivas". En González CussaC, José Luis/ Gómez Colomer, Juan Luis. Terrorismo y proceso penal acusatorio. Valencia: Tirant lo Blanch, p. 72; AвADINsKY (2013) 15-16.

52 Llobet Anglí (2008) p. 39; Abadinsky (2013) 16.

53 Como señala Llobet Anglí (2008) p. 41 el crimen organizado no altera el continente democrático, sino el contenido. En cambio, el terrorismo afecta a ambos. 
te argumentar el porqué de la intervención anticipada del Estado. Esencialmente, son dos las posiciones que se presentan. Una de ellas asume que el bien jurídico protegido tiene un carácter supraindividual, ya sea el orden público, la paz social o el monopolio estatal de la violencia. La otra en cambio, se funda en que los tipos penales en cuestión se anticipan a la protección de aquellos intereses que se verían cuestionados por la asociación, a través de los delitos-fines de esta.

Empero, antes de entrar a su examen quisiera realizar algunas precisiones que permitirán comprender de mejor forma lo que a continuación se expondrá. Es necesario destacar algunas particularidades de la criminalidad organizada que permitan separarla de otras formas de criminalidad en las que también puede apreciarse una organización. En efecto, es preciso distinguir entre criminalidad como empresa de criminalidad en la empresa. Si bien puede parecer sutil la distinción precedente, su precisión permitirá claridad respecto del objeto de análisis y por ende, discernir acerca de sus particularidades.

Cuando se habla de criminalidad como empresa se apunta, justamente, a aquellas organizaciones cuya dirección principal, a través de todo un programa criminal elaborado al efecto, es la obtención de ganancias ilícitas. Es decir, se está frente a organizaciones o estructuras asociativas cuyo eje central es la comisión de delitos, para alcanzar, como propósito final, beneficios económicos. Por tal motivo, como se destacó supra, es determinante disponer de todo un arsenal de medidas penales que tengan como eje central la ablación de tales provechos económicos. Estas disposiciones, para su efectividad, no solo deben tener una mirada a futuro, en el sentido de impedir que estas empresas sigan actuando, anulándolas económicamente, y con ello, evitando que aumenten su caudal pecuniario, sino también deben dirigirse al pasado, privándolas de las ganancias ilícitamente obtenidas. En Italia, por ejemplo, se regula el llamado comiso ampliado - confisca allargata-, que se impone sobre aquellos bienes que se presumen provienen de actividades ilícitas. Lo fundamental no es si estos recursos se identifican con el delito por el cual es condenado-como sucede con el comiso clásico-, sino que se impone cuando se considera que se trata de bienes que presumiblemente tienen un origen ilícito, al no corresponder, por ser desproporcionado, al rédito o actividades económicas desempeñadas por el condenado. Por ello, en Italia se lo identifica más bien con un comiso al patrimonio, más que uno sobre los bienes ${ }^{54}$.

54 Carnevali (2010) 314 y ss.; Fornari, Luigi (1997). Criminalità del profitto e tecniche sanzionatorie. Confisca e sanzione pecuniarie nel diritto penale “moderno". Padua: Cedam, pp. 63 y ss.; Alfonso, Robert (2005). "I problemi e le prospettive del sequestro e della confisca dei patrimoni mafiosi”, En Parano, Carola/Centonze, Alessandro (ed.). L'attività di contrasto alla criminalità organizzata. Milán: Giuffrè, pp. 234 y ss. 
Al contrario, cuando se habla de criminalidad en la empresa, los problemas a resolver son otros y se abordan más bien dentro de la esfera del Derecho penal económico. Es decir, se está frente a estructuras organizativas que no han sido creadas para delinquir. Por el contrario, se organizan con fines lícitos, pero que, dentro de su contexto empresarial, se cometen ocasionalmente delitos. En consecuencia, son otros los problemas que en esta esfera se pretenden resolver -que como es obvio no serán examinados en este trabajo-. Por ejemplo, si a la empresa se le puede atribuir las consecuencias del delito, en cuanto a si ha contribuido como sujeto autónomo de imputación ${ }^{55}$.

No se puede negar que la distinción delineada entre ambas formas de criminalidad puede pecar de ser más bien difusa, pues también en el contexto criminal intervienen empresas lícitas ${ }^{56}$. No obstante, lo esencial es considerar el objetivo o programa criminal que se ha delineado dentro del contexto empresarial, a saber, si se constituyen para cometer delitos y, de este modo, lucrar ilegalmente. Dicho en otros términos, si es posible considerar a la empresa, en cuanto tal, una organización criminal ${ }^{57}$.

\section{2) POSICIONES EN RELACIÓN AL BIEN JURÍDICO PROTEGIDO. ALGUNAS CONSIDERACIONES RESPECTO A LOS CRITERIOS DE IMPUTACIÓN}

Como se indicó, en la doctrina se han elaborado, fundamentalmente, dos tesis a fin de precisar cuál es el bien jurídico protegido en los delitos asociativos. Aquellas que apuntan un objeto jurídico de orden colectivo y las que, conforme a la llamada teoría de la anticipación, afirman que los bienes jurídicos que se amparan guardan relación con los delitos-fines de la organización. En consecuencia, hay que precisar su esfera de actuación.

La primera de las posturas mencionadas, que se puede decir mayoritaria, tiene como punto de partida la afirmación de que se está frente a un

55 Con detalle, Artaza Varela, Osvaldo (2013). La empresa como sujeto de imputación de responsabilidad penal. Fundamentos y limites. Madrid: Marcial Pons.

56 Como apunta, Sotomayor Acosta, Juan Oberto (2010). "Criminalidad organizada y criminalidad económica: los riesgos de un modelo diferenciado de Derecho penal”. Revista de Estudios de la Justicia. $\mathrm{N}^{\circ} 12$, p. 231, realizar una distinción entre criminalidad organizada y criminalidad económica es una tarea compleja. En este mismo sentido, Foffani, Luigi (2001). "Criminalidad organizada y criminalidad económica". Revista penal, N 7, p. 56, al señalar que se produce una osmosis sustancial entre estos dos fenómenos, pues la criminalidad organizada es por naturaleza económica y la criminalidad económica es cada vez más organizada. Es así, que en la literatura criminológica norteamericana para refererirse a la criminalidad organizada se habla de "enterprise crime".

57 ZúNíiga Rodríguez, Laura (2011). "Autoría y participación en el ámbito de la criminalidad organizada a la luz del Derecho comparado y del Derecho internacional”. En MontoyA, Yvan. Criticas al funcionalismo normativista y otros temas actuales del Derecho penal. Lima: Palestra editores, p. 73. 
injusto autónomo, que debe entenderse independientemente de los delitos que pueden llegar a cometerse dentro de la esfera de la organización. Es decir, se trata de un injusto sistémico que servirá de basamento para determinar la responsabilidad de quienes la conforman.

Pues bien, tomando en consideración el presupuesto anterior, a saber, que es la propia organización criminal, en sí misma, la que conforma un sujeto del injusto penalmente relevante, es que el objeto de protección es de orden colectivo. En efecto, lo que se ampara sería la paz o la seguridad pública o, como afirman algunos, el orden público ${ }^{58}$. Sin embargo, como ya se puso en evidencia supra, las dificultades para constreñir el contenido de estos objetos han sido permanentes. Es así, que se presentan serios cuestionamientos para poder distinguir la tutela de estos bienes colectivos con aquellos que son efectivamente erosionados por los delitos que se cometen por la asociación -en los términos de Carrara, entre daño mediato y daño inmediato- ${ }^{59}$. Justamente y a fin de paliar tales controversias acerca de lo amparado por estas figuras, es que se propone hablar de la autotutela del poder del Estado ${ }^{60}$. Según esta posición, la sola existencia de la asociación ilícita supone una negación a la hegemonía y poder del Estado, por cuanto la organización se conforma como una institución regida por su propio ordenamiento, ajena a las reglas propias del Estado. Como podrá suponerse, no se presentan particulares distinciones con las otras nociones ya criticadas, pues el concepto de autotutela del Es-

58 Guzmán Dalbora, José Luis (2009). "Objeto jurídico y accidentes del delito de asociaciones ilícitas”. En Guzmán Dalbora, José Luis. Estudios y defensas penales, 3a ed. Santiago: Editorial LexisNexis, p. 156 y ss.; Grisolía, Francisco (2004). "El delito de asociación ilícita”. Revista Chilena de Derecho. Vol 31, N¹, p. 79, afirma que además del orden y la seguridad públicos se ve afectado el derecho constitucional de asociación por su ejercicio abusivo; Pastor Muñoz, Nuria (2005). Los delitos de posesión y los delitos de estatus: una aproximación politico-criminal y dogmática. Barcelona: Atelier, p. 66, señala que en estos delitos la falta de peligrosidad objetiva se suple con la manifestación de la peligrosidad subjetiva , que es un comportamiento perturbador para la sociedad por cuanto lesiona la seguridad normativa, que es un elemento que pertenece al núcleo de la sociedad; ZúNíga RodrígueZ (2009) 268 afirma que la lesividad del injusto de la organización criminal está dada por la lesión de la seguridad colectiva, caracterizada como situación de peligro hipotético para los bienes jurídicos del programa criminal; Lampe (2003) 129; para Faraldo Cavana, (2012) 236 lo que se protege es un bien jurídico colectivo, la seguridad ciudadana, entendida en su sentido material y objetivo de prevención de la comisión de delitos y faltas. Ya Carrara (1985) Vol. VIII, $\$$ 3039, p. 144, destacaba que: "Las asociaciones constituidas con el fin de cometer delitos, son y deben ser castigadas en todo gobierno como delito autónomo, a causa del peligro social que resulta del solo hecho de formarse". (Cursiva en el original).

59 Sobre el punto, Medina Schulz, Gonzalo (2013). "El injusto de la asociación ilícita como problema de la estructura de afectación del bien jurídico". En VVAA. La ciencia penal en la Universidad de Chile. Libro homenaje a los profesores del Departamento de Ciencias Penales de la Facultad de Derecho de la Universidad de Chile, Santiago: Facultad de Derecho de la Universidad de Chile, p. 492; Ziffer, Patricia (2005). El delito de asociación ilícita. Buenos Aires: Ad-Hoc, p. 39.

60 Es la posición de García-Pablos de Molina (1977). Las asociaciones ilícitas en el Código penal. Barcelona: Bosch, pp. 142 y ss. 
tado es tan difuso y poroso como lo puede ser el de orden público. Además, tiende a confundir o identificar el bien jurídico penalmente protegido con el sujeto pasivo del delito, que vendría a ser el propio Estado, con lo cual podría tratarse, incluso, de un concepto peligroso por su eminente sostén autoritario ${ }^{61}$.

Cancio Meliá plantea, particularmente respecto de las organizaciones terroristas y de otras de similar entidad en cuanto a su poder, que lo que cimenta su punición es la arrogación de estas del monopolio estatal de la violencia en cuanto se trata de organizaciones que cuestionan las normas del Estado ${ }^{62}$. Afirma Cancio que la dimensión específica del injusto de asociación de la asociación criminal está dada por la pretensión de ocupar un lugar (ilegítimo) en la vida pública. Asimismo, resalta este autor. "Por lo tanto, se trata de una arrogación de organización no solo en el sentido de que se arroga una organización ajena, sino, además, que es una organización delictiva quien se la arroga: la organización delictiva se arroga el ejercicio de derechos pertenecientes al ámbito de soberania del Estado. Solo si se vincula de este modo la emergencia de la organización con el incremento fáctico de la peligrosidad que esta supone, se percibe con claridad el especifico significado de la actuación colectiva de las organizaciones criminales: pone en cuestión el monopolio de la violencia que corresponde al Estado"63.

Según mi parecer, lo expuesto por Cancio no supondría un cambio mayor a lo ya afirmado anteriormente, pues se presentan las mismas dificultades para lograr asir un concepto claro acerca de lo protegido. En todo caso, sí estimo que se exponen buenos argumentos para poder explicar el alcance de aquellas organizaciones con particular capacidad lesiva, donde puede cuestionarse el monopolio de la violencia que le corresponde al Estado. Con todo, cabe preguntarse qué sucede con aquellas asociaciones que son inidóneas para poner en riesgo el monopolio estatal. Como, por lo demás, acontece con buena parte de las asociaciones, y que, incluso, se puede desprender de algunas hipótesis del artículo 292 del Código penal chileno. En todo caso, el propio Cancio ha destacado qué organizaciones deberían comprenderse en el ámbito típico, pues no pueden ser asociaciones criminales cualquier agrupación que persiga la comisión de delitos. Es imperioso que dispongan de algún grado de fortaleza, en cuanto a su estructura interna, como para poder desafiar al Estado64.

61 Al respecto, GuZmán Dalbora (2009) 141 y ss.

62 Cancio Meliá, Manuel (2008). "El injusto en los delitos de organización: peligro y significado”. En Cancio Meliá, Manuel/ Silva Sánchez, Jesús María, Delitos de organización. Montevideo: B de F, pp. 73 y ss.

63 Cancio Meliá (2008) 75. (La cursiva es mía); sobre lo tratado, Mañalich (2011) 290.

64 Cancio Meliá (2008) 83; 428 y ss. Sobre este planteamiento, Silva Sánchez, Jesús María (2008). "Introducción”. En Cancio Meliá, Manuel/ Silva Sánchez, Jesús María. Delitos de organización. Montevideo: B de F, p. 4. 
Para la otra tesis, que se comprende dentro de la llamada teoría de la anticipación, los delitos de organización deben entenderse como dimensiones institucionales que favorecen la comisión de delitos dentro de su contexto ${ }^{65}$. Considerado desde esta perspectiva, el castigo por los hechos vinculados a la actividad de organizaciones criminales se plantea como una anticipación a la protección de aquellos bienes jurídicos que se pueden ver afectados por los delitos-fin de la asociación delictiva ${ }^{66}$. Subsiguientemente, si tiene lugar un incremento de peligrosidad representada por la organización, se justificaría entonces, anticipar la intervención punitiva. Lo que se protege son aquellos bienes jurídicos puestos en peligro por las actividades desplegadas por la organización -intereses que ya están amparados en la parte especial-. No se estaría frente un interés autónomo, constituido por la asociación ${ }^{67}$.

No se castiga pues, por el solo hecho de la existencia de la organización criminal -como lo presenta la tesis anterior-, sino en la medida que se está frente a un estado de cosas que permite afirmar que se favorecerá la comisión de delitos que son los fines de la asociación. Es decir, la aportación a través de la organización supone un peligro para el bien o bienes jurídicos concretos. Como se examinará a continuación, para Silva Sánchez esta concepción teórica, cimentada en la anticipación tuitiva, permitiría explicar adecuadamente el fundamento de la imputación respecto de quienes son los miembros. Asimismo, qué criterios deben aplicarse tratándose de los colaboradores externos de la organización criminal. Cuestión tan debatida en Italia con el llamado concurso externo. Y es que la responsabilidad, como se explicará infra, debe estructurarse atendiendo a su propia actuación y no por formar parte de un sistema asocial que afectaría la paz pública o el orden público ${ }^{68}$.

Precisamente, atendiendo las tesis examinadas en torno al bien jurídico es que surgen posturas divergentes en relación a los criterios de imputación. En este contexto, también se aprecian dos grandes posiciones. Por un lado, el llamado modelo de transferencia que se aplica tratándose de

65 Así, Silva SÁnchez, Jesús María (2008). “La ‘intervención a través de la organización’. ¿Una forma moderna de participación en el delito?”. En Cancio Meliá, Manuel/ Silva Sánchez, Jesús María, Delitos de organización. Montevideo: B de F, pp. 87 y ss., quien señala que las primeras tesis en este sentido fueron expuestas por Hans Joachim Rudolphi en el Libro Homenaje a H.J. Bruns de 1978. También, Cancio Meliá (2008) 398; Sánchez García de LA PAZ (2008) 674.

66 Silva Sánchez (2008) 98; Mañalich (2011) 291.

67 Si se atiende a la regulación de la asociación ilícita en el Código penal chileno, en donde se determina su penalidad conforme a los delitos que se pretenden cometer a través de la asociación -ya sean crímenes o simples delitos-, parece discutible aceptar sin más el carácter autónomo de la figura en comento. Así lo expone, Medina Schulz (2013). 483. Para Silva SÁNCHEz (2008) 116, no resulta admisible la tipificación genérica de un delito de pertenencia a una organización criminal en que se haga abstracción de la gravedad de los delitos-fin. 
aquellas propuestas que afirman la configuración de un injusto autónomo y la existencia de bienes jurídicos colectivos. La otra postura, que puede denominarse Modelo de responsabilidad por el hecho propio del miembro o colaborador entiende que los delitos de organización conforman ciertas dimensiones institucionales que favorecen la comisión de delitos dentro de su esfera.

Tratándose del modelo de transferencia, la sanción penal a los miembros de la organización hallaría su basamento en el peligro que representa tal agrupación para la estabilidad social, entendiendo esta como la paz, seguridad u orden público. Dicho peligro persistiría en la medida que se mantenga la organización. Al respecto, cabe consignar que uno de sus presupuestos esenciales es su carácter estable y permanente. Por ende, en la medida en que los miembros sustenten la organización tal peligro sigue presente.

No cabe duda que el modelo expuesto presenta ciertas ventajas a la hora de imputar responsabilidad de sus integrantes. Y es que al tratarse de un bien jurídico supraindividual puesto en peligro por la organización, los criterios de imputación serían más laxos respectos de quienes son sus miembros. Bastaría pues, acreditar la pertenencia a la organización, sin atender mayormente el aporte, esto es, independiente de la contribución individual. Se trataría más bien de un delito de adhesión.

Silva Sánchez es bastante claro para poder comprender lo expuesto: "El titulo de imputación tendría que definirse así: 'a todos y cada uno de los miembros de la organización se les responsabiliza del estado de cosas peligroso para la paz pública que es la organización, aunque cada uno de los miembros por separado no constituya, obviamente, dicho peligro para la paz, ni tampoco pueda afirmarse que domine el referido peligro colectivo" "69.

Por de pronto surgen una serie de preguntas no fáciles de dilucidar, ¿puede considerarse que por formar parte de una organización se cuestiona el bien jurídico tutelado? ¿Basta afirmar la presencia de un injusto sistémico para cimentar la responsabilidad de cada uno de los miembros de la organización?

Me parece necesario establecer ciertas precisiones que autoricen distinguir la aportación de cada uno de los miembros de la organización. Incluso siendo integrante no es suficiente para atribuir responsabilidad.

Justamente, el modelo de responsabilidad por el hecho propio del miembro o colaborador va en la dirección reseńada. Por de pronto, debe tenerse presente que el castigo que se impone por los actos vinculados a la organización se fundamentarían en la anticipación tuitiva para determinados bienes jurídicos. Se presenta pues, un aumento de peligrosidad representado por la estructura organizativa criminal explicando así la anticipación

Silva SÁNChez (2008) 104. (La cursiva es mía). 
punitiva. Pues bien, teniendo presente lo anterior, se colige que lo amparado son aquellos bienes jurídicos que podrían lesionarse con la ejecución de los delitos-fines. Para tal efecto, la asociación debe conformarse en una estructura generadora de riesgos, es decir, una fuente de peligro incrementado, que adquiere una dinámica autónoma. En definitiva debe ser idónea desde una perspectiva ex ante para llevar a cabo los delitos comprendidos en su programa criminal ${ }^{70}$.

Por lo anterior, el castigo no halla su basamento por el solo hecho de la existencia de la organización, sino en la medida que crea una estado de cosas que permite considerar que favorece la comisión de delitos-fines. Es decir, su aportación a través de la organización supone un peligro para un bien jurídico concreto. Se es responsable por el propio comportamiento de quien forma parte, en la medida de su propia actividad favorecedora de la comisión de delitos; es decir, no se pena por el solo hecho de ser miembro, ni menos por la sola peligrosidad que la organización representaría para determinados bienes jurídicos ${ }^{71}$.

Los argumentos expuestos precedentemente nos servirán para poder comprender los criterios para imputar la responsabilidad de quienes participan a través de la organización ${ }^{72}$.

Como primera cuestión fundamental y que la distingue de la tesis anterior: la organización, en cuanto tal y por el hecho de estructurarse, no es suficiente para ser valorada como un injusto merecedor de pena; es decir, no se instituye el castigo por la sola circunstancia de la pertenencia a la organización -cuestión meramente formal-, sino que es esencial precisar en qué medida su comportamiento pueda valorarse comprendido dentro una participación en el delito-fin concreto ${ }^{73}$. En consecuencia, serán autores aquellos miembros de la organización que hayan intervenido directamente en la comisión de delitos contra bienes jurídicos concretos -delitos-fin de la organización- o la dominen a través de la organización. En cambio, si se observa una ausencia de conducta que no permite apreciar elementos mínimos favorecedores de hechos concretos dentro del contexto de la organización, serán estimados miembros pasivos de la organización y no deben ser sancionados.

En lo que respecta a quienes no forman parte de la organización, pero pueden ser calificados como colaboradores externos - por ejemplo, políticos, funcionarios públicos, jueces, empresarios- solo pueden ser

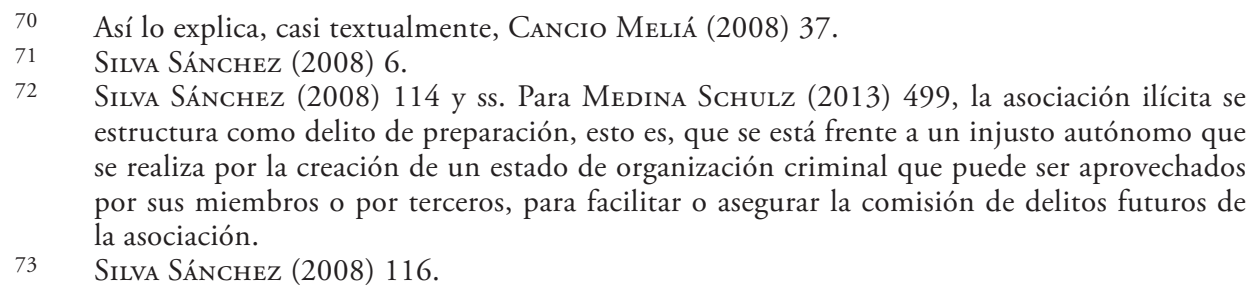
estructura como delito de preparación, esto es, que se está frente a un injusto autónomo que se realiza por la creación de un estado de organización criminal que puede ser aprovechados por sus miembros o por terceros, para facilitar o asegurar la comisión de delitos futuros de la asociación.

73 Silva Sánchez (2008) 116. 
castigados por el o los delitos que efectivamente hayan cometido -por ejemplo, prevaricación, cohecho, entre otros-. Pero no deberían ser sancionados por un delito asociativo ${ }^{74}$.

El desvalor de la organización halla, esencialmente, su basamento en su naturaleza favorecedora de determinados delitos, lo que autoriza precisar de qué modo intervienen cada uno de sus miembros. Por tanto, la sola circunstancia de ser miembro no autoriza a ser castigado por el o los delitos cometidos a través de la organización. El soporte de la sanción se encuentra en la medida que se trate de miembros que hayan realizado actuaciones favorecedoras, a través de la organización, del delito-fin ${ }^{75}$.

74 Precisamente, en este último punto ha generado particulares discusiones en Italia, donde se ha recurrido al llamado concurso externo - concorso esterno- para fundamentar el castigo por el tipo asociativo de quienes sin formar parte de la organización colaboraron en la consecución de sus objetivos (los dos casos más emblemáticos en que se discutió la aplicación del concurso externo fueron los casos Carnevale y Mannino). Se ha señalado en apoyo de la aplicación del concurso externo que aquel que ocasionalmente realiza actividades que refuerzan a la asociación criminal, sí está facilitando su existencia; esto es, quien contribuye dolosamente a reforzar la asociación, sabiendo que su conducta tendrá esta eficacia favorecedora, también concurre en la comisión del delito asociativo. La figura del concurso externo se ha aplicado para enfrentar la criminalidad de tipo mafioso y terrorista, castigando a aquellos sujetos que no formando parte de la organización, cooperan con ella, favoreciéndola. La discusión se ha presentado por cuanto al no formar parte de la asociación no realiza en rigor una conducta típica: no es un “asociado". Por tanto, no podría contribuir materialmente en la causación del hecho delictivo quien no forma parte de la asociación. Sin embargo, para entender la respuesta italiana hay que tener presente que se ha optado por un modelo unitario de autor -art. 110 y ss. del Código penal-, por lo que todos aquellos que concurren, cualquiera sea la contribución, a causar un hecho delictivo responden como intervinientes del mismo. Por cierto, no debe entenderse que todos respondan con la misma pena, sino que se gradúa dentro de un mismo marco penal, precisándose para cada uno de los intervinientes conforme concurran o no ciertas circunstancias indicadas en el art. 133 del Código penal. Al respecto, Marinucci, Giorgio/Dolcini, Emilio (2012). Manuale di Diritto Penale, 4a ed. Milán: Giuffré, p. 434 quienes agregan: "El problema de la configuración de un concurso de personas en los delitos asociativos se advierte, sobre todo, en relación a lo obrado por algunas categorías de profesionales (abogados, magistrados, empresarios) que supone una objetiva facilitación de las actividades de las asociaciones criminales. Para una correcta solución del problema es decisivo distinguir entre conductas que se comprenden en el ejercicio de las facultades o de los deberes inherentes a aquellas diversas profesiones y conductas que, en cambio, están fuera. Al respecto, en doctrina oportunamente se ha avanzado en propuestas de reformas legislativas, que contengan la explícita enunciación del criterio distintivo". También sobre el concurso externo, entre otros, Insolera, Gaetano (2008). "Ancora sul problema del concorso esterno nei delitti associativi". Rivista italiana di diritto e procedura penale, p. 632 y ss; Manna, Adelmo (1994) "L'ammisibilità di un c.d. concorso "esterno" nei reati associativi, tra esigenze di politica criminale e principio di legalità". Rivista italiana di diritto e procedura penale. p. 1189 y ss.; Muscatiello, Vincenzo Bruno (1999). "Per una caratterizzazione semantica del concorso esterno". Rivista italiana di diritto e procedura penale, p. 184 y ss.; Bertorotta, Francesco (1998). "Concorso eventuale di persone e reati associativi” en Rivista italiana di diritto e procedura penale, pp. 1273 y ss.

75 Como afirma Silva SÁnchez (2008) 117: "La fundamentación de esta intervención implica una matización normativista de las reglas tradicionales de intervención en el delito. La figura puede denominarse "intervención (o participación) a través de una organización” y cons- 
Finalmente, se puede sancionar tanto por el delito de pertenencia a la organización como por el delito-fin, por cuanto este último no tiene por qué satisfacer todo el desvalor representado por el delito de peligro ${ }^{76}$.

\section{5) Hacia una propuesta normativa. Tratamiento particular DE LA CRIMINALIDAD ORGANIZADA}

A continuación, se expondrá -sin mayores detalles- el tratamiento normativo de los delitos asociativos, tanto la legislación nacional como comparada. El propósito perseguido es resolver cuán conveniente puede estimarse la consagración de un injusto particular que abarque los comportamientos propios de la criminalidad organizada. Lo anterior, fundado sobre la base aquí defendida de que se está frente a una modalidad específica de una asociación ilícita.

En apoyo a una elaboración de presupuestos típicos determinados, propios del crimen organizado, subyace la idea de que se está frente a estructuras que manifiestan una particular peligrosidad. En efecto, tal como la propia Convención de Palermo afirma, se trata de organizaciones que tienen la capacidad de cometer delitos graves ${ }^{77}$; es decir, debe tratarse de estructuras organizativas que tengan la idoneidad necesaria como para poder emprender delitos de especial magnitud ${ }^{78}$.

Naciones de cultura jurídica similar a la nuestra, como son los casos de España e Italia, disponen no solo de tipos penales relativos a la asociación criminal, sino también de tipos específicos para abarcar aquellas organizaciones más peligrosas. Es así, que el Código penal español, en el artículo 515 regula las asociaciones ilícitas y en el artículo 570 bis se hace cargo de las organizaciones criminales. Por su parte, el Código penal italiano, aborda la asociación para delinquir en el artículo 416, disponiendo en el artículo 416 bis la asociación de tipo mafioso.

tituye una categoría complementaria del "dominio de organización", propio de los "aparatos organizados de poder", entre los que se cuentan las organizaciones criminales".

76 Silva SÁNCHez (2008) 101 (n. 169).

77 La Convención de Palermo, entiende por delito grave: "Art. 2 b) Por "delito grave" se entenderá la conducta que constituya un delito punible con una privación de libertad máxima de al menos cuatro años o con una pena más grave". Sánchez García de LA PAZ (2001) 676 y ss.; Carnevali (2010) 285.

78 Cavaliere Antonio (2003). "Tipicità ed offesa nei reati associativi”. En Patalano, Vincenzo (ed.). Nuove strategie per la lotta al crimine organizzato transnazionale. Turín: Giappichelli, p. 86; Aleo, Salvatore (2005). "Associazione, organizzazione, concorso esterno". En Parano, Carola/Centonze, Alessandro (ed.). L'attività di contrasto alla criminalità organizzata. Milán: Giuffrè, p. 180; Faraldo Cavana (2012) 236. 


\section{1) LA LEGISLACIÓN CHILENA SOBRE ASOCIACIÓN ILÍCITA}

Su regulación sobre la materia que es objeto de examen se caracteriza por cierta dispersión y un tratamiento inorgánico. En efecto, se requiere de una mayor sistematicidad y evitar que se aborde en distintos cuerpos normativos.

Es así, que en el Código Penal, en los artículos 292 y siguientes se encuentra tratado el delito de asociación ilícita, dentro del título VI que comprende los delitos contra el orden y la seguridad pública cometidos por particulares. También es posible hallar otras disposiciones que se refieren al delito de asociación ilícita, tanto dentro del mismo código como en leyes especiales. En efecto, en la Ley de Seguridad interior del Estado -artículo $1^{\circ} \mathrm{f}$ )-; Ley sobre conductas terroristas -artículo $2 \mathrm{~N}^{\circ} 5-$; Ley sobre tráfico ilícito de estupefacientes -artículo $16-{ }^{79}$; Ley que sanciona el lavado de activos -artículo 28-; asociación para la trata de personas y tráfico ilícito de migrantes-artículo 411 quinquies-, y Ley 20.357 que tipifica los crímenes de lesa humanidad y genocidio y crímenes y delitos de guerra -artículo 15-. También, debe citarse el artículo 369 ter del Código penal, que alude a organizaciones delictivas que comenten delitos vinculados a la corrupción de menores.

Por de pronto, de este elenco se puede afirmar que su tratamiento es bastante particular y algo confuso. En algunos casos, solo se remite a lo dispuesto en el Código penal -artículos 292 y ss.-, sin disponer un tratamiento punitivo diverso. Así sucede, con la trata de personas y el tráfico de migrantes y con lo expresado en el artículo 369 ter del Código penal que solo habla de organizaciones delictivas, sin agregar nada más. En otros casos, si bien se remiten a las normas del delito de asociación ilícita, ofrecen un sistema punitivo más gravoso. Es el caso, de la ley sobre conductas terroristas y de crímenes de lesa humanidad y genocidio y crímenes y delitos de guerra. Por último, en las leyes de tráfico ilícito de estupefacientes y de lavado de activos se brinda una regulación particular, diversa a la del Código penal. Lo mismo acontece con la ley de seguridad interior del Estado, que de forma bastante escueta solo indica que se debe castigar a los que se se asociaren en partidos políticos, movimientos o agrupaciones.

Es importante hacer presente que en todas estas disposiciones solo se alude a los que se asociaren u organizaren, pero no se establece una regulación particular que permita comprender qué se entiende por asociación,

\footnotetext{
79 Carnevali, Raúl/Fuentes, Hernán (2008). "Informe jurídico sobre la eventual aplicación del delito de asociación ilícita establecido en el art. 16 de la Ley $N^{\circ} 20.000$ ”. Política Criminal, $\mathrm{N}^{\circ}$ 6, D1, 2008.
} 
como sí sucede, por ejemplo, en la regulación italiana y española, o en la propia Convención de Palermo ${ }^{80}$.

Cabe consignar que en el Anteproyecto de Código penal de 2005 se trata el delito de asociación ilícita en los artículos 374 y siguientes. Así también, el artículo $392 \mathrm{~N}^{\circ} 5$ para los delitos de terrorismo. Pues bien, las disposiciones citadas ofrecen una regulación más simple que la del Código actual, ya que solo exige que se destine a la comisión de delitos, sin hacer referencia a atentados al orden social, buenas costumbres, personas o propiedades. Por otra parte, se agrega a los financistas dentro de los sujetos que reciben un tratamiento más riguroso, equivalente a quienes están en el mando. En cuanto a la eximente, se dispone en los mismos términos que el actual artículo 295, pero sí incorpora una atenuación en caso de que los delitos ya se hubieren ejecutado y se preste una cooperación eficaz, definiéndose esta. Por último, se establece el delito de omisión de información y la correspondiente eximente, en términos equivalentes a los del artículo 295 bis $^{81}$.

\section{2) DERECHO COMPARADO}

A continuación, me referiré a las legislaciones de aquellos países europeos que ejercen una importante influencia cultural en nuestra esfera jurídica. Si bien es una exposición escueta y no acompañada de un análisis crítico, permite conocer el tratamiento que dichas naciones ofrecen para enfrentar las asociaciones criminales. Asimismo, servirá de apoyo para la tarea posterior dirigida a la elaboración de normas penales que comprendan las conductas propias de la criminalidad organizada.

En el caso español, sí se observa un tratamiento particularmente llamativo, diríase más bien, excesivamente riguroso y, sobre todo, engorroso. En efecto, existen dos normas fundamentales que se refieren a la figura en comento: el artículo 515 que hace referencia al delito de asociación ilícita, dentro del capítulo sobre los delitos relativos al ejercicio de los derechos fundamentales y libertades públicas, y el artículo 570 bis referido al delito de organización criminal -incorporado en la reforma de noviembre de 2010-, comprendido en el título de los delitos contra el orden públi$\mathrm{co}^{82}$. Esta última figura tiene su explicación en la necesidad de adecuarse

80 Grisolía (2004) 81; Etcheberry, Alfredo (1998). Derecho penal. IV Tomo. 3a ed. Santiago: Editorial Jurídica de Chile, p. 317.

81 Ver "Anteproyecto de Código Penal Chileno de 2005, elaborado por la Comisión Foro Penal" (2006). Politica Criminal, No 1, D1 (http://www.politicacriminal.cl/n_01/pdf_01/d_1. pdf) (consultado el 26 de febrero de 2014),

82 Entre otros, Corcoy Bidasolo, Mirentxu/ Mir Puig, Santiago (dir.) (2011). Comentarios al Código penal. Reforma LO 5/2010. Valencia: Tirant lo Blanch, p. 1113 y ss.; VIVEs ANTón, Tomás et al. (2010). Derecho penal. Parte Especial. $3^{\circ}$ ed. Valencia: Tirant lo Blanch, p. 772 y ss.; García Albero, Ramón (2011). "De las organizaciones y grupos criminales". 
a las normas internacionales y europeas ya citadas. A dichas disposiciones generales, deben agregarse aquellos preceptos que sancionan asociaciones para cometer delitos en particular. Solo por citar a modo de ejemplo: artículo 177 bis sobre trata de personas; 183, abusos sexuales; 187 y 189, corrupción y prostitución de menores; 264.3, daños informáticos; 305 bis 1., defraudación a la Hacienda pública; 309, tráfico de drogas, y 572, terrorismo.

Por cierto, llama la atención la técnica legislativa española, pues se producen evidentes problemas de solapamiento normativo, ya que todos estos casos en particular, pueden comprenderse en el delito asociación ilícita o, en su caso, en el de organización criminal. No parece pues, necesario ir creando un tipo ad hoc para castigar la pertenencia a la organización. Por otro lado, no puede dejarse de lado el problema interpretativo entre los tipos penales de los artículos 515 y 570 bis, ya que atendiendo lo dispuesto en el artículo 8.4 del Código penal -principio de alternatividad en un concurso de leyes- tornaría inaplicable la primera de ellas ${ }^{83}$.

En lo que respecta a la legislación alemana, el tratamiento que ofrece para estos delitos de organización resulta bastante más acotada que la española que exhibe un exagerado catálogo de delitos ${ }^{84}$. El Código penal de 1871/1975 incorpora dentro del título de los delitos contra el orden público, la figura de conformación de asociaciones criminales $-\$ 129-$. Se configura el delito en la medida que la asociación tenga por objeto o esté orientada a la comisión de hechos punibles, comprendiéndose a quienes formen parte como miembro, hagan propaganda o la apoyen. Asimismo, se sanciona más gravemente a los que dirigen la asociación. Se prescinde de la pena en aquellos casos en que el tribunal valore que la responsabilidad del partícipe sea menor y su colaboración no tiene mayor relevancia. Cabe destacar, que también se dispone de una eximente o una atenuante, cuando se observe que el autor ha procurado impedir la continuación de la organización o la comisión de los delitos, o revela a la autoridad los planes de la asociación.

Por su parte, el Código penal tudesco dispone en el $\$ 129$ a el delito de organización terrorista y en el $\$ 127$ la figura de conformación de gru-

En Quintero Olivares, Gonzalo. Comentarios a la Parte Especial del Derecho penal. 9a ed. Cizur Menor: Aranzadi, pp. 2218 y ss.

83 Al respecto, González Rus, Juan José (2013). "Aproximación político-criminal a la regulación de la criminalidad organizada después de la reforma de 2010”. En GonzÁlez Rus, Juan José (dir). La criminalidad organizada. Valencia: Tirant lo Blanch, pp. 100 y ss., quien destaca las incoherencias del modelo y la "triple vía" de punición; Faraldo Cavana (2012) 104; Villacampa Estiarte (2012) 23.

84 Entre otros, Laufhütte, Heinrich Wilhelm/Rissing-Van SaAn, Ruth/Tiedemann, Klaus (ed.) (2009). Strafgesetzbuch: Leipziger Kommentar. Grosskommentar. Vol. 5. 12a ed., Berlín: Gruyter Recht, pp. 306 y ss.; Schönke, Adolf/Schröder, Horst (2006). Strafgesetzbuch: kommentar. 27a ed. Munich: Beck, pp. 1276 y ss. 
pos armados. Esta última no supone que se está frente a una estructura organizada, propia de una asociación.

Empero, como consecuencia de las normativas europeas los Estados de dicho continente han ido modificado sus regulaciones, ya sea incorporado nuevas figuras o modificado las existentes. Supra se expuso lo sucedido en España. En el caso alemán, tratándose de $\$ 129$ se incorporó en 2005 un párrafo en que se precisa un aumento de las penas cuando el objetivo de la organización son determinados delitos -indicados en el $\$ 100$ c 2. del Código procesal penal-. Entre las figuras indicadas están: la puesta en peligro del Estado democrático de Derecho; falsificación de dinero; delitos contra la libertad sexual; producción, distribución de material pornográfico infantil, y delitos contra la libertad personal, comprendiendo la trata de personas.

Por último, se puede citar el delito de organizaciones criminales y terroristas en el extranjero, incorporado al Código penal en 2002. Apunta fundamentalmente a establecer reglas de persecución, sobre todo a la autorización del Ministerio de Justicia.

El caso italiano es particularmente interesante, pues junto con el delito de asociación para delinquir dispuesto en el artículo 416 del Código penal, contempla el delito de asociación de tipo mafioso en el artículo 416 bis -incorporado en 1982-85. Ambos establecidos dentro del título de los delitos contra el orden público. Es claro que esta última disposición obedece a las particularidades propias de la sociedad italiana, pero se destaca por ser una de las primeras normas relativas a un tipo de organización criminal especialmente peligrosa, como es la mafia. Ahora bien, es cierto que existen componentes culturales que inciden en el desarrollo de estos grupos organizados, como son el sentido de pertenencia a una determinada organización. Al respecto, basta tener en cuenta que el propio Código Penal italiano, en su artículo 416 bis, se refiere a la omertá, como una particularidad muy propia de las sociedades mafiosas, que consiste en un suerte de solidaridad, interna y externa. Lo indicado precedentemente, también pone en evidencia que no es posible generalizar determinadas propuestas legislativas traspasándolas, así sin más, a otras realidades nacionales. Lo dispuesto en la citada norma italiana expresa una manifestación de las asociaciones criminales de dicha nación, que no necesariamente se reflejan en otras culturas, como lo es hablar del método mafioso expresado en el artículo 416 bis $^{86}$.

85 Así, Marinucci, Giorgio/Dolcini, Emilio (dir.) (2006). Codice Penale commentato. 2a ed. Milán: Ipsoa, pp. 3039 y ss.; Moccia, Sergio (ed.) (1999). Criminalità organizzata e risposte ordinamentali. Nápoles: Edizioni Scientifiche Italiane; Giostra, Glauco/Insolera, Gaetano (ed) (1995). Lotta alla criminalità organizzata: gli strumenti normativi. Milán: Giuffrè.

86 Para Moccia (2003) 256, el artículo 416 bis es excesivamente descriptivo, casuístico, en que se mezclan elementos normativos, naturalistas, sociológicos, menoscabando el mandato de determinación. 
El artículo 416 que trata la figura genérica precisa que la asociación la conforman tres o más personas y que tienen por objeto la comisión de delitos. Se distingue, a efectos de la sanción, entre quienes participan en la organización y los que la promueven y la dirigen. Asimismo, la pena se aumenta si se emplean armas o si la asociación la integran diez o más personas. En el Código penal también se encuentran tipificadas, entre otras, las asociaciones subversivas - art. 270- y antinacionales -art. 271-, la constitución de asociaciones de carácter internacional sin autorización gubernativa -art. 273-, la asociación con propósito terrorista y de subversión del orden democrático -art. 270 bis-. Sin perjuicio de las anteriores, también es posible encontrar disposiciones en leyes especiales, como es el caso de la asociación militar con fines políticos -artículo 1 del decreto legislativo n. 43 de 1948- y las asociaciones dedicadas al tráfico de drogas y sustancias psicotrópicas -artículo 74 del decreto del Presidente de la República n. 309, de 9 de octubre de 1990-.

En el Código penal austríaco, dentro de los delitos contra el Estado, se disponen en el $\$ 278$ la formación de organizaciones entre tres o más personas para la comisión de, entre otros delitos, asesinato o actos de violencia contra la integridad física y contra la vida, secuestro, trata de esclavos, o de tráfico de personas. En el \$278a castiga el delito de organización criminal, aludiendo a la fundación o participación como miembro en una asociación similar a la empresa con gran número de personas, señalando los delitos que son objeto de la organización. Así, delitos contra la vida, la salud, la libertad o el patrimonio, delitos de corrupción o contra la Administración de Justicia, dirigidos a obtener una importante influencia en la política o en la economía. Esta figura se asemeja al artículo 416 bis italiano. Por último, el $\$ 278$ b se refiere a la organización terrorista.

El Código penal suizo sanciona en el artículo 260 ter el delito de organización criminal -en el título de los delitos contra la tranquilidad pública-, disponiendo que tanto la integración como el apoyo a una organización criminal que mantenga en secreto su estructura y la identidad de sus miembros y que tenga el propósito de cometer delitos violentos o de enriquecerse utilizando medios delictivos. Por su parte, el artículo 275 ter tipifica el delito de asociación ilícita, dentro del título de los delitos contra el Estado y la defensa nacional. Por ello se castiga a quien funda, participa o promueve la fundación de una asociación que se propone realizar conductas punibles como delitos contra el Estado, espionaje político, militar y económico, y contra el orden constitucional.

El Código penal francés se hace cargo de la materia examinada en el libro IV sobre delitos contra la Nación, el Estado y la paz pública, concretamente en los artículos 450-1 y siguientes tipificando el delito de participación en una asociación de malhechores. Se disponen las sanciones 
atendiendo la pena dispuesta para los delitos que son objeto de la organización ${ }^{87}$.

\section{3) HACIA UNA REGULACIÓN DE LA CRIMINALIDAD ORGANIZADA}

A continuación trataré de fundamentar una propuesta de regulación para la asociación criminal. Según mi parecer debe expresarse en una figura básica, definiéndose qué debe entenderse por tal. Asimismo, deben establecerse ciertas circunstancias que pondrían de manifiesto una mayor peligrosidad de la organización; es decir, disponer de ciertos elementos que permitan apreciar que se está frente a una estructura idónea para la consecución de ciertos objetivos comprendidos dentro de un plan criminal. Esto último, a fin de poder abarcar los supuestos que son propios de la llamada criminalidad organizada a que hace referencia la Convención de Palermo.

Ahora bien, dicha Convención se refiere a organizaciones que se dirigen a la comisión de delitos graves. Si bien allí se indica que son tales delitos los que tienen una pena privativa de libertad de al menos cuatro años, me parece que la regulación de qué delitos pueden así calificarse, deben quedar precisados en la parte especial. Es decir, que el legislador resuelva, en cada caso, qué tipos penales se pueden cometer por una organización criminal, recibiendo un tratamiento penal más gravoso. Conforme a lo anterior, estimo que deben considerarse de manera particular los delitos de tráfico ilícito de estupefacientes, terrorismo, trata de personas, tráfico ilícito de personas, lavado de dinero y tráfico de armas. Precisamente, son delitos en los que el crimen organizado tiene una particular incidencia.

En definitiva, se debe regular una figura que trate la Asociación ilícita $o$ delictiva y otra que se haga cargo de la Asociación criminal-supuestos propios del crimen organizado-, precisándose allí los delitos que la conforman -los llamados delitos graves conforme los términos de la Convención-. Luego, en la parte especial se debe indicar el tratamiento penal por la comisión de los delitos cometidos por la Asociación criminal. Además, se deben contemplar supuestos agravados. El sistema propuesto permitiría evitar los solapamientos normativos que tienen lugar en España, con las consiguientes dificultades interpretativas que se manifiestan.

\subsection{1.) Propuesta de articulado}

Se entiende por Asociación ilícita (o delictiva): Toda asociación que tenga por objeto la perpetración de delitos, como asi también, aquella que

87 Larguier, Jean/Conte, Philippe/Larguier, Anne-Marie (2005). Droit pénal spécial. 13a ed. París: Dallos, pp. 366 y ss. 
después de su conformación se destina a su comisión, se considera ilicita, importando un delito.

Para estos efectos, se entiende por asociación ilicita toda organización compuesta por tres o más personas, que con carácter estable en el tiempo y actuando concertadamente tenga como fin la comisión de delitos, ya sea para obtener beneficios económicos o de otro orden.

Se entiende por Asociación criminal: Es asociación criminal toda asociación ilicita que tenga por objeto la perpetración de los delitos de tráfico ilicito de estupefacientes, terrorismo, trata de personas, tráfico ilicito de personas, lavado de dinero y tráfico de armas.

A fin de evitar problemas interpretativos se define qué debe entenderse por asociación delictiva. Para el efecto se ha seguido, tanto lo dispuesto en la Convención de Palermo como en la legislación italiana, española y austríaca. Ahora bien, en cuanto a la denominación también puede pensarse, a fin de expresar de mejor forma lo que se pretende castigar, en Asociación para delinquir, como en el caso italiano, o Asociación delictiva. Tales calificaciones permiten distinguirla con claridad de la Asociación criminal que, precisamente, se refiere a los supuestos más graves propios de la criminalidad organizada. Como ya se subrayó, la penalidad de la asociación criminal se precisa cuando se tratan los delitos en particular.

Se indica que deben conformarla tres o más personas, tener un carácter estable y que se observe una concertación que permita apreciar un cierto orden, jerarquía y planificación. Además, que se dirijan a la comisión de delitos, con el fin de obtener beneficios económicos o de otro orden. Se trata pues, de delitos de tendencia interna trascendente, particularmente, delitos mutilados en dos actos ${ }^{88}$.

Se exigen tres o más personas, pues de este modo se aprecia de mejor forma una organización, donde la voluntad común es la que prima, pudiendo de este modo reducirse la libertad decisoria individual ${ }^{89}$. Por otro lado, se dispone como fin el de orden lucrativo, por ser el que se manifiesta más nítidamente en las organizaciones criminales. Empero, ello no impide comprender otros fines, pues a través de la expresión $o$ de otro orden se abarcan supuestos diversos a los lucrativos. Así por ejemplo, un propósito terrorista, político o religioso, los que luego son tratados en cada caso particular. Lecciones de Derecho Penal chileno. Parte General. 2a ed. Santiago: Editorial Jurídica de Chile, pp. 191 y ss. afirman que son suficiente dos. Al respecto, Gajardo Orellana, Tania (2010). "Elemento del tipo de asociación ilícita del artículo 292 del Código penal. Propuesta, análisis doctrinal y jurisprudencial". Revista Jurídica del Ministerio Público, No 45, p. 231-232. Por estimar que se debe exigir al menos tres personas, Grisolía (2004) 80. 
Cuando se afirma en el primer inciso, que también se consideran ilícitas aquellas organizaciones que después de su conformación se destinan a la comisión de delitos, se apunta a los casos en que la asociación se ha estructurado para fines lícitos, pero a través de ella se cometen delitos. Por ejemplo, empresas de importación que sirven para el tráfico de drogas. También lo dispone el artículo 515 del Código español.

Participación en la asociación ilícita. Por el solo hecho de formar parte en la asociación ilicita, se impondrá una pena.

Quienes financien, coordinen, promueven o dirigen la asociación ilicita serán castigados con la pena de presidio mayor.

En aquellos casos en que la asociación ilicita tenga un número superior a diez miembros, las penas señaladas anteriormente se impondrán en su grado máximo.

Como sucede no solo en nuestro Código, sino también en los examinados, se debe distinguir, a fin de fijar la sanción, el papel que desempeńa cada uno de los integrantes de la asociación. Probablemente, lo novedoso se encuentra en el inciso final cuando se alude al número de los miembros. En este punto se ha seguido la ley italiana y la española, que atienden a la mayor peligrosidad que supone una organización compuesta por un número importantes de personas. Se ha preferido, por razones de seguridad jurídica, señalar expresamente la cantidad y no recurrir a la expresión "elevado número" como lo hace la española.

Tratándose de los colaboradores externos, es decir, aquellos que no forman parte de la asociación solo pueden ser castigados por el o los delitos cometidos, pero no por la figura asociativa -atendida las argumentaciones expuestas precedentemente-. Podría, en su caso, contemplarse la aplicación de una agravante especial.

Circunstancias agravantes. Las penas indicadas se elevarán en un grado, cuando la asociación emplea para lograr sus objetivos:

1. Medios violentos o recurra a la intimidación.

2. Instrumentos peligrosos o que por sus características facilitan la ejecución de los delitos o la impunidad de quienes intervienen.

3. Realicen el cohecho de funcionarios públicos para la consecución de los objetivos de la organización.

Se pretende a través de esta norma indicar aquellos medios que expresen la mayor peligrosidad de una organización. De algún modo, se quiere dar cuenta de circunstancias que destacan en una organización, en términos similares al artículo 570 bis español o al 416 bis italiano. Es decir, disponer de normas que se hagan cargo de organizaciones que tienen una especial capacidad para cometer delitos de mayor gravedad o que recurren a medios propios de asociaciones de tipo mafioso.

En este sentido, debe entenderse que estos medios son consustanciales a la organización, esto es, forman parte del programa criminal, de 
manera que pueda hacerse un juicio colectivo o global del proceder de la organización. Por tanto, acciones aisladas que no encuentran un apoyo del grupo o no se hallan en las bases mismas de la asociación, no dan lugar a la agravación.

Exención y atenuación de la pena. Las penas señaladas en los artículos anteriores no se impondrán respecto de quienes antes de ejecutarse alguno de los delitos que son objeto de la asociación y antes de ser perseguidos, revelen a la autoridad la existencia de dicha asociación, sus miembros, planes y propósitos.

En caso que alguno de estos delitos ya se hubiesen ejecutado, dicha revelación será circunstancia atenuante de responsabilidad penal, siempre que constituya una cooperación eficaz que conduzca al esclarecimiento de los hechos investigados o permita la identificación de sus responsables; o sirva para prevenir o impedir la perpetración o consumación de otros delitos de igual o mayor gravedad. En estos casos, el tribunal podrá reducirla pena hasta en dos grados.

Para estos efectos, se entiende por cooperación eficaz el suministro de datos o informaciones precisas, verídicas y comprobables, que contribuyan necesariamente a los fines señalados en el inciso primero.

No hay mayor novedad, pues la eximente se encuentra en el actual artículo 295 del Código penal. Asimismo, y junto con la atenuante, se dispone en el código alemán, austríaco, suizo y francés, solo por citar algunos. Es una herramienta de indudable eficacia para enfrentar figuras como las examinadas, más aún si se trata de organizaciones con una especial peligrosidad.

A modo de conclusión, es cierto que para enfrentar la criminalidad organizada se deben disponer de medidas de orden económico, considerando que son razones de orden lucrativo las que, fundamentalmente, motivan su conformación. Sin embargo, tampoco se puede discutir la innegable eficacia disuasiva que pueden tener los delitos asociativos. En este sentido, la estructuración de figuras penales que recojan los presupuestos más relevantes que caracterizan a la criminalidad organizada y que la distingan de otras formas de asociación, pueden conformar instrumentos eficaces para su persecución.

\section{BIBLIOGRAFÍA}

- Abadinsky, Howard (2013). Organized Crime. 10a ed. Belmont: Wadsworth.

- Albanese, Jay S. (2011). Organized Crime in our times. $3^{\mathrm{a}} \mathrm{ed}$. Burlington: Elsevier.

- Aleo, Salvatore (2005). "Associazione, organizzazione, concorso esterno". En Parano, Carola/Centonze, Alessandro (ed.). L'attività di contrasto alla criminalità organizzata. Milán: Giuffrè. 
- Alfonso, Robert (2005). "I problemi e le prospettive del sequestro e della confisca dei patrimoni mafiosi", En Parano, Carola/ Centonze, Alessandro (ed.). L'attività di contrasto alla criminalità organizzata. Milán: Giuffrè.

- Anteproyecto de Código Penal Chileno de 2005, elaborado por la Comisión Foro Penal" (2006). Politica Criminal, No 1, D1 (http:// www.politicacriminal.cl/n_01/pdf_01/d_1.pdf) (consultado el 26 de febrero de 2014).

- Artaza Varela, Osvaldo (2013). La empresa como sujeto de imputación de responsabilidad penal. Fundamentos y limites. Madrid: Marcial Pons.

- Barazzetta, Aurelio (2006). "Art. 416 bis". En Marinucci, Giorgio/Dolcini, Emilio (dir.), Codice Penale commentato, 2a ed. Milán: Ipsoa.

- Bertorotta, Francesco (1998). "Concorso eventuale di persone e reati associativi" en Rivista italiana di diritto e procedura penale.

- Betti, Stefano (2003). "New prospects for inter-state co-operation in criminal matters: The Palermo Convention". International Criminal Law Review, 3.

- Block, Antón (1974). The Mafia of a Sicilian Village 1860-1960, Oxford: Basil Blackwell.

- Callegari, André Luis (2010). "Crimen organizado: concepto y posibilidad de tipificación delante del concepto de la expansión del derecho penal". Revista Derecho penal y criminología. Vol. XXXI, Nº 91.

- Cancio Meliá, Manuel (2008). "El injusto de los delitos de organización: peligro y significado". En Cancio Meliá, Manuel/ Pozuelo Pérez, Laura (coord). Política criminal en vanguardia. Cizur Menor: Thomson Civitas.

- Cancio Meliá, Manuel (2008). "El injusto en los delitos de organización: peligro y significado". En Cancio Meliá, Manuel/ Silva SÁnchez, Jesús María, Delitos de organización. Montevideo: B de F.

- Cancio Meliá, Manuel (2010). Los delitos de terrorismo: estructura típica e injusto. Madrid: Reus.

- Carnevali, Raúl (2005) "Las políticas de orientación a la víctima examinadas a la luz del Derecho penal". Revista de Derecho de la Pontificia Universidad Católica de Valparaiso, XXVI, Semestre I.

- Carnevali, Raúl (2010). "La criminalidad organizada. Una aproximación al derecho penal italiano, en particular la responsabilidad de las personas jurídicas y la confiscación”. Ius et Praxis, año $16, \mathrm{~N}^{\circ} 2$.

- Carnevali, Raúl/Fuentes, Hernán (2008). "Informe jurídico sobre la eventual aplicación del delito de asociación ilícita establecido en el art. 16 de la Ley $\mathrm{N}^{\circ}$ 20.000". Política Criminal, Nº, D1, 2008. 
- Carrara, Francesco (1985). Programa de Derecho criminal. Parte General. vol. IV. Traducción de Ortega Torres, José y Guerrero, Jorge. Bogotá: Temis.

- Castaldo, Andrea (2005). "La naturaleza económica de la criminalidad organizada”. En YAсовUCCI, Guillermo (coord.). El crimen organizado. Desafios y perspectivas en el marco de la globalización. Buenos Aires: Abaco de Roberto Depalma.

- Castaldo, Andrea/Naddeo, Marco (2010). Il denaro sporco. Prevenzione e repressione nella lotta al riciclaggio, Padua: Cedam.

- Cavaliere Antonio (2003). "Tipicità ed offesa nei reati associativi". En Patalano, Vincenzo (ed.). Nuove strategie per la lotta al crimine organizzato transnazionale. Turín: Giappichelli.

- Corcoy Bidasolo, Mirentxu/ Mir Puig, Santiago (dir.) (2011). Comentarios al Código penal. Reforma LO 5/2010. Valencia: Tirant lo Blanch.

- Di Fiore, Gigi (2005). La camorra e le sue storie. Turín: Utet.

- Di Nicola, Andrea (2002). "La criminalitá economica organizzata: implicazioni di politica penale". Rivista Trimestrale di Diritto Penale dell'Economia.

- Etcheberry, Alfredo (1998). Derecho penal. IV Tomo. $3^{a}$ ed. Santiago: Editorial Jurídica de Chile.

- Faraldo Cavana, Patricia (2012). Asociaciones ilicitas y organizaciones criminales en el Código penal español. Valencia: Tirant lo Blanch.

- Fernández Cruz, José Ángel (2002). “La “empresa criminal”: Los "delitos de comercio" ilícito como factor de aparición del fenómeno del "blanqueo de capitales" ", Revista de Estudios Criminológicos y Penitenciarios, 5.

- Ferrajoli, Luigi (1995). Derecho y razón. Teoría del garantismo penal. Traducción de Andrés Ibáñez, Perfecto et al., Madrid: Trotta.

- Ferrajoli, Luigi (2000). "Sul diritto penale minimo (risposta a Giorgio Marinucci e a Emilio Dolcini)”. Foro italiano, Parte Quinta.

- Ferrajoli, Luigi (2009). "Criminalidad y globalización”. En Carbonell, Miguel/ Vásquez, Rodolfo (Comp.), Globalización y Derecho. Quito: Ministerio de Justicia y Derechos Humanos.

- Foffani, Luigi (2001). "Criminalidad organizada y criminalidad económica”. Revista penal, N 7 .

- Fornari, Luigi (1997). Criminalità del profitto e tecniche sanzionatorie. Confisca e sanzione pecuniarie nel diritto penale “moderno". Padua: Cedam.

- Fornasari, Gabriele (2002). "Le strategie di contrasto alla criminalità orgnizzata: aspetti comparatistici nell' esperienza europeo-continentale". En Fornasari, Gabriele (ed.). Le strategie di contrasto alla criminalità orgnizzata nella prospettiva di diritto comparato. Padua: Cedam. 
- Gajardo Orellana, Tania (2010). "Elemento del tipo de asociación ilícita del artículo 292 del Código penal. Propuesta, análisis doctrinal y jurisprudencial". Revista Jurídica del Ministerio Público, $\mathrm{N}^{\circ} 45$.

- García Albero, Ramón (2011). "De las organizaciones y grupos criminales”. En Quintero Olivares, Gonzalo. Comentarios a la Parte Especial del Derecho penal. 9a ed. Cizur Menor: Aranzadi.

- García-Pablos de Molina (1977). Las asociaciones ilícitas en el Código penal. Barcelona: Bosch.

- Gilligan, George (2007). "Business, risk and organized crime". Journal of Financial Crime.

- Giostra, Glauco/Insolera, Gaetano (ed) (1995). Lotta alla criminalità organizzata: gli strumenti normativi. Milán: Giuffrè.

- González Cussac, José Luis (2006). "El Derecho penal frente al terrorismo. Cuestiones y perspectivas”. En González Cussac, José Luis/ Gómez Colomer, Juan Luis. Terrorismo y proceso penal acusatorio. Valencia: Tirant lo Blanch.

- González Rus, Juan José (2013). “Aproximación político-criminal a la regulación de la criminalidad organizada después de la reforma de 2010”. En González Rus, Juan José (dir). La criminalidad organizada. Valencia: Tirant lo Blanch.

- Grisolía, Francisco (2004). "El delito de asociación ilícita". Revista Chilena de Derecho. Vol 31, $\mathrm{N}^{\circ} 1$.

- Guzmán Dalbora, José Luis (2009). “Objeto jurídico y accidentes del delito de asociaciones ilícitas”. En Guzmán Dalbora, José Luis. Estudios y defensas penales, $3^{\mathrm{a}}$ ed. Santiago: Editorial LexisNexis.

- Hardouin, Patrick (2009). "Bank governance and public-private partnership in preventing and confronting organized crime, corruption and terrorism financing". Journal of financial crime. Vol. $16 \mathrm{~N}^{\circ} 3$.

- Insolera, Gaetano (2008). "Ancora sul problema del concorso esterno nei delitti associativi". Rivista italiana di diritto e procedura penale.

- Jiménez de Asúa, Luis (1970). Tratado de Derecho penal. Tomo VII. Buenos Aires: Losada.

- Lampe, Ernst-Joachim (2003). "Injusto del sistema y sistema de injusto". Traducción de Gómez-Jara, Carlos. En Lampe, ErnstJoachim. La dogmática jurídico-penal entre la ontología social y el funcionalismo. Lima: Grijley.

- Larguier, Jean/Conte, Philippe/Larguier, Anne-Marie (2005). Droit pénal spécial. 13a ed. París: Dallos.

- Laudati, Antonio (2003). "Criminalità organizzata e riciclaggio". En Patalano, Vincenzo (editor), Nuove strategie per la lotta al crimine organizzato transnazionale. Turín: Giappichelli. 
- Laufhütte, Heinrich Wilhelm/Rissing-Van SaAn, Ruth/ Tiedemann, Klaus (ed.) (2009). Strafgesetzbuch: Leipziger Kommentar. Grosskommentar. Vol. 5. 12a ed., Berlín: Gruyter Recht.

- Llobet Anglí, Mariona (2008). Terrorismo y "guerra" contra el terror: limites de su punición en un Estado democrático. Tesis doctoral, Universidad Pompeu Fabra, Barcelona.

- Lo Monte, Elio (2003). "Ecomafia: il controllo penale tra simbolicità ed effettività". En Patalano, Vincenzo (ed.), Nuove strategie per la lotta al crimine organizzato transnazionale. Turín: Giappichelli.

- Mangione, Angelo (2008). “ “Law \& Economics” e diritto penale: paradigma a confronto nell'analisi delle politiche di contrasto alla criminalità organizzata”. En Maugeri, Anna Maria (ed.), Le sanzioni patrimoniali come moderno strumento di lotta contro il crimime: reciproco riconoscimento e prospettive di armonizzazione. Milán: Giuffrè.

- Manna, Adelmo (1994) "L'ammisibilità di un c.d. concorso "esterno" nei reati associativi, tra esigenze di politica criminale e principio di legalità". Rivista italiana di diritto e procedura penale.

- Mañalich, Juan Pablo (2011). "Organización delictiva. Bases para su elaboración dogmática en el derecho penal chileno". Revista Chilena de Derecho. Vol. $38 \mathrm{~N}^{\circ} 2$.

- Marine, Frank (2006). "The effects of organized crime on legitimate businesses". Journal of Financial Crime. Vol. $13 \mathrm{~N}^{\circ} 2$.

- Marinucci, Giorgio/Dolcini, Emilio (1999). "Diritto penale 'minimo' e nuove forme di criminalità'. Rivista italiana di diritto e procedura penale.

- Marinucci, Giorgio/Dolcini, Emilio (2012). Manuale di Diritto Penale, 4a ed. Milán: Giuffré.

- Marinucci, Giorgio/Dolcini, Emilio (dir.) (2006). Codice Penale commentato. 2a ed. Milán: Ipsoa.

- Medina Schulz, Gonzalo (2013). "El injusto de la asociación ilícita como problema de la estructura de afectación del bien jurídico". En VVAA. La ciencia penal en la Universidad de Chile. Libro homenaje a los profesores del Departamento de Ciencias Penales de la Facultad de Derecho de la Universidad de Chile, Santiago: Facultad de Derecho de la Universidad de Chile.

- Michelini, Gualtiero/Polimeni, Gioacchino (2007). "Il fenomeno del crimine transnazionale e la Convenzione delle Nazione Unite contro il crimine organizzato transnazionale". En Rosi, Elisabetta (ed.), Criminalità organizzata transnazionale e sistema penale italiano. Milán: Ipsoa.

- Militello, Vincenzo (2004). "La pertenencia a una organización criminal como tipo penal modelo europeo". Persona y Derecho. N 51. 
- Militello, Vincenzo (2005). "Le strategie di contrasto della criminalità organizzata transnazionale tra esigenze di politica criminale e tutela dei diritti umani”. En Parano, Carola/Centonze, Alessandro (ed.), L'attività di contrasto alla criminalità organizzata. Milán: Giuffrè.

- Moccia, Sergio (1999). "Prospettive non 'emergenziali' di controllo dei fatti di criminalità organizzata. Aspetti dommatici e di politica criminale". En Moccia, Sergio (ed.), Criminalità organizzata e risposte ordinamentali, Nápoles: Edizioni Scientifiche Italiane.

- Moccia, Sergio (ed.) (1999). Criminalità organizzata e risposte ordinamentali. Nápoles: Edizioni Scientifiche Italiane.

- Moccia, Sergio (2003). El Derecho penal entre ser y valor. Traducción de Bonnano, Antonio. Montevideo: B de F.

- Molinario, Alfredo (1949). El bien jurídico garantizado con la incriminación de los delitos contra el orden público o la paz pública. Montevideo: Impresora uruguaya.

- Muscatiello, Vincenzo Bruno (1999). "Per una caratterizzazione semantica del concorso esterno". Rivista italiana di diritto e procedura penale.

- Nunzi, Alfredo (2005). "La Convenzione delle Nazioni Unite contro la criminalità organizzata transnazionale". En BAssiouni, Cherif M. (ed.), La cooperazione internazionale per la prevenzione $e$ la repressione della criminalitá organizata e del terrorismo. Milán: Giuffrè.

- Orlova, Alexandra (2005). “Umbrellas' or 'building blocks'? Defining international terrorism and transnational organized crime in international law". Houston Journal of International Law. Vol. 27, $\mathrm{N}^{\circ} 2$.

- Pastor Muñoz, Nuria (2005). Los delitos de posesión y los delitos de estatus: una aproximación politico-criminal y dogmática. Barcelona: Atelier.

- Peccioli, Annamaria (2005). Unione Europea e criminalità transnazionale. Turín: Giappichelli.

- Pérez Cepeda, Ana (2004). Globalización, tráfico internacional ilícito de personas y derecho penal. Granada: Ed. Comares.

- Perri, Frank S./Brody, Richard G. (2011). "The dark triad: organized crime, terror and fraud". Journal of Money Laundering Control. Vol 14, $\mathrm{N}^{\circ} 1$.

- Plantamura, Vito (2007). "Ecomafia, reati associativi e diritto penale dell'economia". Rivista Trimestrale di Diritto Penale dell'Economia.

- Politoff, Sergio/Matus, Jean Pierre/Ramírez, María Cecilia (2004). Lecciones de Derecho Penal chileno. Parte General. 2a ed. Santiago: Editorial Jurídica de Chile. 
- Rodríguez Collao, Luis/ Ossandón Widow, Magdalena 2008). Delitos contra la función pública. 2a ed. Santiago: Editorial Jurídica de Chile.

- Rojas Aravena, Francisco (2006). El crimen organizado internacional: una grave amenaza a la democracia en América Latina y el Caribe. San José de Costa Rica: Flacso.

- Romano, Salvatore (1966). Storia della mafia. Verona: Mondadori.

- Rosi, Elisabetta (ed.) (2007). Criminalità organizzata transnazionale e sistema penale italiano. Milán: Ipsoa.

- Rovito, Pier Luigi (1999). "Mentalità emergenziale e crimine organizzato: profili storici". En Moccia, Sergio (ed.). Criminalità organizzata e risposte ordinamentali. Nápoles: Edizioni Scientifiche Italiane.

- Salazar, Lorenzo (2005). "Misure di contrasto alla criminalità organizzata elaborate dall'Unione Europea”. En BAssiouni, Cherif M. (ed.), La cooperazione internazionale per la prevenzione e la repressione della criminalitá organizata e del terrorismo. Milán: Giuffrè.

- SÁnchez García de la paz, Isabel (2001). "Función políticocriminal del delito de asociación para delinquir: desde el derecho penal político hasta la lucha contra el crimen organizado”. En Arroyo Zapatero, Luis/Berdugo Gómez de la Torre, Ignacio (directores). Homenaje al Dr. Marino Barbero Santos. In Memoriam. Vol II. Cuenca: Ediciones de la Universidad de Castilla-La Mancha/ Ediciones Universidad de Salamanca.

- Sánchez García de la Paz, Isabel (2008). "Problemas de legitimidad de una respuesta excepcional frente a las organizaciones criminales”. En Cancio Meliá, Manuel/Pozuelo Pérez, Laura (coord). Politica criminal en vanguardia. Cizur Menor: Thomson Civitas.

- Schönke, Adolf/Schröder, Horst (2006). Strafgesetzbuch: kommentar. 27a ed. Munich: Beck.

- Shelley, Louise (1995). "Transnational organized crime: an imminent threat to the nation-state?". Journal of International Affairs. Vol. 48, $\mathrm{N}^{\circ} 2$.

- Silva Sánchez, Jesús M. (2011). La expansión del Derecho penal. Aspectos de la Politica Criminal en las sociedades postindustriales. Montevideo: B de F.

- Silva Sánchez, Jesús María (2008). “Introducción”. En Cancio Meliá, Manuel/ Silva Sánchez, Jesús María. Delitos de organización. Montevideo: B de F.

- Silva Sánchez, Jesús María (2008). "La 'intervención a través de la organización’. ¿Una forma moderna de participación en el delito?”. 
En Cancio Meliá, Manuel/ Silva Sánchez, Jesús María, Delitos de organización. Montevideo: B de F.

- Solís, Luis Guillermo/Rojas Aravena, Francisco (editores) (2008). Crimen organizado en América Latina y el Caribe, Santiago: Catalonia.

- Sotomayor Acosta, Juan Oberto (2010). "Criminalidad organizada y criminalidad económica: los riesgos de un modelo diferenciado de Derecho penal". Revista de Estudios de la Justicia. $\mathrm{N}^{\circ} 12$.

- Szczaranski, Clara (2000). "El Consejo de Defensa del Estado y el control de la criminalidad organizada y del lavado de dinero". En Politoff, Sergio/ Matus, Jean Pierre (coord.). Gran criminalidad organizada y tráfico ilícito de estupefacientes. Santiago: ConoSur.

- Villacampa Estiarte, Carolina (2012). "Trata de seres humanos y delincuencia organizada". In dret. $\mathrm{N}^{\circ} 1$.

- Villegas Díaz, Myrna (2006). "Los delitos de terrorismo en el Anteproyecto de Código Penal". Politica Criminal, No 2, A3.

- Vives Antón, Tomás et al. (2010). Derecho penal. Parte Especial. $3^{\circ}$ ed. Valencia: Tirant lo Blanch.

- Ziffer, Patricia (2005). El delito de asociación ilícita. Buenos Aires: Ad-Hoc.

- Ziffer, Patricia (2008). "El delito de asociación ilícita frente al "Derecho penal de la expansión". En Cancio Meliá, Manuel/ Pozuelo Pérez, Laura (coord.). Política criminal en vanguardia. Cizur Menor: Thomson Civitas.

- Zúniga Rodríguez, Laura (2006). "Criminalidad organizada, Derecho penal y sociedad. Apuntes para el análisis". En SANZ Mulas, Nieves (coord.). El desafio de la Criminalidad Organizada. Granada: Comares.

- ZúÑiga Rodríguez, Laura (2009). Criminalidad organizada y sistema de derecho penal. Contribución a la determinación del injusto penal de organización criminal. Granada: Comares.

- ZúÑiga Rodríguez, Laura (2011). "Autoría y participación en el ámbito de la criminalidad organizada a la luz del Derecho comparado y del Derecho internacional". En Montoya, Yván. Criticas al funcionalismo normativista y otros temas actuales del Derecho penal. Lima: Palestra editores. 